\title{
Positional Preferences and Efficiency in a Dynamic Economy *
}

\section{Thomas Aronsson $^{a}$, Sugata Ghosh ${ }^{b}$, Ronald Wendner ${ }^{c}$}

$a$

$b$

Umeå School of Business, Economics and Statistics, Umeå University, Sweden

Department of Economics and Finance, Brunel University London, U.K.

Department of Economics, University of Graz, Austria

January 30, 2020

\begin{abstract}
Based on an endogenous growth model, this paper characterizes the conditions under which positional preferences do not give rise to intertemporal distortions as well as derives an optimal tax policy response in cases where these conditions are not satisfied. In our model, individuals can be positional both in terms of their consumption and wealth, the relative concerns partly reflect comparisons with people in other countries, and we distinguish between a (conventional) welfarist government and a paternalist government that does not respect positional preferences. We also extend the analysis to a multi-country framework and show that Nash-competition among local paternalist governments leads to a global social optimum, whereas Nash-competition among local welfarist governments does not.
\end{abstract}

Keywords and Phrases: Positional preferences, efficiency, intertemporal distortions, welfarist government, paternalist government, endogenous growth.

JEL Classification Numbers: E71, H11, O43

*We thank Philippe Bontems, Daniel Buncic, Reto Foellmi, Gerhard Glomm, Michael Greinecker, Olof Johansson-Stenman, Marko Köthenbürger, Christoph Kuzmics, Marc Law, Nathalie Mathieu-Bolh, Xavier Raurich, Michael Scholz, Stephen Turnovsky and participants of the European Public Choice Society 2018 Meeting for particularly useful discussions. Aronsson and Wendner gratefully acknowledge research grants from The Marianne and Marcus Wallenberg Foundation (MMW 2015.0037). We retain sole responsibility for any remaining errors. 


\section{Introduction}

This paper analyzes the research question of whether positional preferences give rise to intertemporal economic distortions. It also characterizes a corrective tax policy in cases where such distortions arise.

As positional preferences imply that people impose externalities on one another, one might argue that this type of preferences do give rise to distortions and therefore calls for corrective taxation. In this study, we show that the research question is not that easily answered. At least four characteristics are important in this context. First, are individuals positional with respect to consumption or wealth, or both? Second, are wealth or consumption reference levels, with which individuals compare their own consumption and wealth, respectively, determined solely within the home country or also partly abroad? Third, do governments use a welfarist objective or some paternalist objective for determining which kind of distortions (if any) are observed and how to correct for them? Fourth, do governments of different jurisdictions coordinate their policies? The paper develops an endogenous growth model to examine the conditions under which positional consumption and/or wealth concerns lead to intertemporal distortions from the perspective of national governments, as well as the conditions under which the choices made by Nashcompeting national governments lead to a globally optimal resource allocation.

Positional preferences, manifested through (status-driven) social comparisons, have played an important role in recent research on optimal taxation and public expenditure (e.g., Aronsson and Johansson-Stenman, 2008; Wendner and Goulder, 2008; Eckerstorfer and Wendner, 2013; Kanbur and Tuomala, 2013; Ghosh and Wendner, 2018). Consumption positionality is, in this literature, meant to imply that individuals not only derive utility from their own absolute consumption (broadly defined), as in standard economic models; they also derive utility from 
their own consumption relative to that of referent others. ${ }^{1,2}$ A typical result in this literature is that positional concerns motivate a significant corrective element in the tax system, due to the externality that the underlying social comparisons give rise to, which tends to imply much higher marginal income tax rates, or much higher taxation of certain commodities, compared to models without any social comparisons among individuals/households.

Yet, very few studies have tried to systematically characterize the conditions under which positional preferences are distortive (such that policy intervention is really called for), and when they are not. The main purpose of the present paper is to fill this gap by deriving necessary and sufficient conditions under which positional preferences distort the intertemporal consumption choice. For deriving those conditions, we take a broad perspective by considering: (i) positionality with respect to consumption as well as wealth; (ii) consumption-/wealth reference levels that are partially determined by foreign countries; (iii) welfarist or paternalist governments; and (iv) a case with international policy cooperation. Our approach is described in greater detail below.

Contrary to most previous studies, which concentrate on how positional concerns affect the atemporal consumption-leisure choice and the policy implications thereof (e.g., Aronsson and Johansson-Stenman, 2008, 2018; or Aronsson et al., 2018), we consider an endogenous growth model where individuals can be positional both in terms of their consumption and wealth. ${ }^{3}$ In this setting, we derive the conditions

\footnotetext{
${ }^{1}$ The standard reference for status-driven, conspicuous consumption is Veblen (1899), even if the recognition of such concerns is of much older date (see the literature review in Section 2). See also Duesenberry's (1949) theory of relative income and Hirsch (1977) for a definition of "positional goods".

${ }^{2}$ That positional preferences is a well-researched topic is evident from the fact that a quick search in Google Scholar with the phrase, "keeping up with the Joneses", brings forth about 10,000 (working) papers. To trace the reason for that, we can consider a specific example. For quite some time, the SUV sector has been the fastest growing segment of the auto industry in major regions (see e.g., Euromonitor International 2016). Referring to this development, which is clearly indicative of the positionality of preferences, Abel (2005) makes the following comment: 'Conventional economic theory assumes that the utility of a person ... is independent of the consumption of others. Yet a visit to the parking lot of a suburban shopping mall may tempt an economist to question this independence."

${ }^{3} \mathrm{~A}$ related model was used by Ghosh and Wendner (2018) to analyze optimal income and
} 
under which these relative concerns cause distortions, whereby the decentralized outcome diverges from the social optimum.

A central aspect of our analysis is the distinction between two types of social objectives: a welfarist objective and a paternalist objective. The welfarist objective represents the conventional approach and means that the government (or social planner $)^{4}$ respects all aspects of consumer preferences and forms the social objective thereupon. Consequently, a welfarist government seeks to internalize the externalities that relative consumption and wealth concerns give rise to. In contrast, the paternalist objective implies that the government does not respect the individual preferences for relative consumption and relative wealth, although it respects all other aspects of consumer preferences. As such, this government "launders" the individual preferences when forming the social objective. The intuition is that a paternalist government would like the individuals/households to behave as if these concerns were absent and will design the public policy accordingly. Although welfarism is the common approach to normative economics, it is not uncontroversial when individuals engage in social comparisons. This is because concerns for relative consumption and relative wealth can be interpreted as expressions of envy; an anti-social preference that several authors have argued against including in a social welfare function (e.g., Sen, 1979; Harsanyi 1982; Goodin, 1986). This suggests to us that a broad perspective is useful when characterizing the distortive effects of social comparisons. ${ }^{5}$

Another central aspect is that relative concerns may partly emanate from social

consumption taxes; yet, without any reference to multi-country economies or paternalism, which are core issues here (see below).

${ }^{4}$ Although conceptually different in principle, we will use the terms "government" and "social planner" interchangeably in what follows.

${ }^{5}$ In reality, it is not easy to identify governments of specific countries as being one of these two types. However, the philosophy of Nordic countries is generally to assign greater importance to the public sector under the notion that consumers may face difficulties in making informed decisions, and the requisite information can sometimes be acquired better by public agencies, which could thereby be viewed as paternalist in nature. Government expenditure as a percentage of GDP was more than $50 \%$ in these countries compared to less than $35 \%$ for the US in 2005 . Of this, welfare spending was above $35 \%$ for these countries compared to about $20 \%$ for the US: see The Nordic Model (2007, ch. 8, Table 8.1). 
comparisons with people in other countries. Indeed, recent empirical evidence suggests that the importance of inter-country comparisons has increased over time (e.g., Clark and Senik, 2011; Becchetti et al., 2013). To incorporate such comparisons in the analysis, we follow the methodological approach outlined by Aronsson and Johansson-Stenman (2015). In our setting, this means decomposing the measures of reference consumption and reference wealth - the variables by which each individual compares his/her own consumption and wealth, respectively - in two parts: one originating from within-country comparisons and the other from comparisons with people in other countries (e.g., as transmitted by social media, internet, and television on a daily basis). ${ }^{6}$ Although the reference measures are exogenous to any individual (who is assumed to act as an atomistic agent), the domestic part of these measures are endogenous to a national government while the foreign part is exogenous. Note that cross-country comparisons have implications for the distortions that positional concerns give rise to. Under welfarism, cross-country comparisons would imply that a national government (whose objective is a national social welfare function) fails to implement the global social optimum, due to that the international externalities would still remain un-internalized in such a setting, whereas the policy responses by national governments may coincide with the responses by a (hypothetical) global social planner under paternalism. The reason is that paternalist governments strive at correcting a (perceived) behavioral failure; not internalizing the externalities that the underlying social comparisons give rise to.

To summarize, the contribution of the paper is twofold. First, we use a more general framework for characterizing the intertemporal distortions caused by positional concerns than earlier studies, which turn out to be special cases of our model. Prior studies on social comparisons in dynamic economies typically look at either consumption positionality or wealth positionality. We demonstrate that the

\footnotetext{
${ }^{6}$ That foreign consumption/wealth is important in our story is reflected in the purchase of luxury goods in foreign markets (31\% of total) or at airports (16\% of total) by consumers of such goods. These proportions rise to $40 \%$ and $20 \%$ respectively when consumers from emerging markets are considered, who typically do not have access to the same range of products or brands that are available in more mature markets: see Global Powers of Luxury Goods 2017, page 5.
} 
wealth and consumption positionalities interact in non-trivial ways. This is true also in Nakamoto (2009) who, like us, considers a preference for wealth in addition to consumption positionality. However, his result that consumption positionality always introduces a distortion is a special case that does not generally hold once households are positional with respect to wealth as well. Specifically, once consumption positionality matches wealth positionality, positional preferences do not cause an intertemporal distortion. Second, we analyze the distortions emanating from positional concerns and the policy implications thereof from the perspectives of welfarist and paternalist governments. Compared to previous research, which emphasizes that the optimal tax policy responses are often surprisingly similar under the two welfare criteria, despite that the motive for corrective taxation differs between them in a fundamental way (Aronsson and Johansson-Stenman, 2018), we demonstrate that distortions and optimal policy responses can be quite different when international externalities are involved.

Our main results are summarized as follows. First, we demonstrate that the existence of a balanced growth path does not imply efficiency. This means that a balanced growth path may exist in spite of intertemporally distortive positional preferences. Second, with a preference for - but without positionality in - wealth, consumption positionality is always distortionary. ${ }^{7}$ Also, the distortion is greater with a paternalist than with a welfarist objective. This is because the welfarist government attaches value to increased relative consumption (due to that it treats the foreign reference measure as exogenous), while the paternalist government, in its social welfare function, does not attach any social value to increased relative consumption; consequently, the saving rate and growth rate are higher for the paternalist government. Third, we show that consumption positionality is not necessarily distortive in the presence of wealth-dependent preferences, as argued above.

Fourth, the endogenous-exogenous composition of the reference levels, as per-

\footnotetext{
${ }^{7}$ Here households, by not taking into account the wealth externality, save less than either type of government would, and consequently the growth rate for the decentralized economy is lower than under a planner.
} 
ceived by national policy makers, impacts on the nature of distortions implied by positional preferences. Thus, positional preferences may give rise to one distortion (like over-saving) according to a welfarist government, while giving rise to the opposite kind of distortion (under-saving) according to a paternalist government. This is a rather interesting case where the apparently puzzling result is consistent from an economic standpoint, but where a judgement on which policy is optimal has ultimately to be dictated by philosophical considerations. To the best of our knowledge, this type of issue has not been systematically investigated before.

Fifth, we characterize, under both types of government, the optimal income tax/subsidy implications in terms of the gap between the private and social marginal rates of substitution between wealth and consumption.

Finally, by considering the domestic and foreign economies simultaneously, and if the positional preferences are distortive, we show that Nash-competing national governments may have incentives to implement a global social optimum if based on paternalist objectives, while the global social optimum typically differs from Nash equilibrium under welfarist objectives.

The paper is structured as follows. Section 2 briefly reviews the literature on positional preferences, highlighting issues of particular importance for the present study. Section 3 presents the endogenous growth model for both the market economy and the social decision-problems. Section 4 derives conditions for non-distortionarity of positional preferences in a "one-country" context by comparing the outcome of the uncontrolled market economy with the resource allocation implemented by a welfarist and a paternalist government, respectively, as well as examines the optimal tax policy implications following from these distortions. Section 5 extends the analysis to a global economy, where a globally optimal (welfarist and paternalist) resource allocation is compared with a non-cooperative Nash-equilibrium from the perspective of the distortions caused by international consumption and wealth comparisons. Section 6 concludes the paper. 


\section{A Brief Literature Review}

The importance of positionality in human behavior was recognized in the early literature. ${ }^{8}$ Following Smith (1759), Veblen (1899), Duesenberry (1949), and other eminent economists, there also exists a large volume of current literature on this issue. In more recent times, Easterlin (1995) demonstrated that while national incomes have increased over the decades, happiness levels have not grown. ${ }^{9}$ One explanation for this Easterlin Paradox is that people have positional preferences, as emphasized by Clark et al. (2008). The recent literature provides abundant significant empirical evidence for positionality in consumer preferences (e.g., Solnick and Hemenway, 1998, 2005; Johansson-Stenman et al., 2002; Johansson-Stenman and Martinsson, 2006). Furthermore, clearly visible goods such as housing - which often represents a significant part of the households' wealth - are more positional than other, less visible goods (Alpizar et al., 2005; Solnick and Hemenway, 2005; Carlsson et al., 2007). A recent brief discussion is provided in Wendner (2014).

As explained in the introduction, an important element of our paper is that in evaluating the distortionary effects of relative concerns, we consider a paternalist government in addition to a welfarist one. This is because several authors, including Sen (1979) and Harsanyi (1982), argue that it is questionable to include "anti-social" preferences, such as envy, in a social welfare function. ${ }^{10}$ Their arguments call for a

\footnotetext{
${ }^{8}$ That social distinction or status is an important motivation of human behaviour was pointed out by Darwin (1871), who emphasized sexual selection besides natural selection (on this, see Truyts (2010)). In his The Republic (Book II), Plato argues: Since ... appearance tyrannizes over truth and is lord of happiness, to appearance I must devote myself. This passage astoundingly resembles Darwin's argument on sexual selection.

${ }^{9}$ This is striking because a well-established empirical finding is that in a given society the rich are happier than the poor: see Clark and Senik (2011). There is both single-country and international evidence showing that the rich are happier than the poor within a given country, that those in richer countries have higher happiness and life satisfaction scores than those in poorer countries (see, e.g., Blanchflower (2008)), and that an increase in individual income over time is associated with increasing happiness.

${ }^{10}$ The following quote from Harsanyi nicely sums up this viewpoint: "It is, of course, well known that a person's preferences may be distorted by factual errors, ignorance, careless thinking, rash judgments, or strong emotions hindering rational choice, etc. Therefore, we may distinguish between a person's explicit preferences, i.e., his preferences as they actually are, possibly distorted by factual and logical errors - and his true' preferences, i.e., his preferences as they would be under 'ideal conditions' and, in particular, after careful reflection and in possession of all relevant
} 
paternalist welfare function that does not attach any social value to increased individual utility caused by higher relative consumption and/or relative wealth. Other authors are more positive as regards the inclusion of positional preferences in a welfare function (Piketty and Saez, 2013, p. 453). Frank (2005) argues that positional concerns, rather than reflecting anti-social preferences, might reflect instrumental reasons such as the need for families to keep up with community spending to be able to live in areas where their children could attend good quality schools. However, irrespective of which perspective one takes, a relevant question is whether positional concerns distort the resource allocation and, in that case, what the optimal policy responses look like. It is interesting to note that the policy rules for optimal marginal income taxation may be quite similar, despite that the welfarist and paternalist governments have different motives for using corrective taxation, as in Aronsson and Johansson-Stenman (2018). Furthermore, in their numerical analysis, they also find that the levels of marginal and average taxation as well as the overall redistribution policy are often quite similar. We extend their analysis to a dynamic model with wealth accumulation, where individuals/households are positional both in terms of their consumption and wealth, and by allowing for social comparisons between (as well as within) countries. ${ }^{11}$

Despite that the policy oriented literature on social comparisons has typically focused on one-country economies, inter-country comparisons have most likely gained importance in recent decades. James (1987) contends that the direction of change in tastes from non-positional to positional consumption has historically to do with

information. In order to exclude the influence of irrational preferences, all we have to do is to define social utility in terms of the various individuals' 'true' preferences, rather than in terms of their explicit preferences." (Harsanyi (1977), p. 29-30). Harsanyi goes further, suggesting that one needs "to disregard, not only preferences distorted by factual or logical errors, but also preferences based on clearly antisocial attitudes, such as sadism, resentment, or malice" (Harsanyi (1977), p. 30 ). In the same vein, Goodin observes that private preferences are suitable for a government objective function only if they are laundered (Goodin (1986)).

${ }^{11}$ Aronsson and Johansson-Stenman (2018), Kanbur and Tuomala (2013), and Micheletto (2011) investigate optimal nonlinear redistributive taxation in the presence of positional preferences in the context of a paternalist welfare criterion, while Dodds (2012) considers linear income taxation. All of these papers are very much in the spirit of the optimal income tax tradition with heterogeneous households. However, none of these papers considers either a dynamic setting, or a preference for wealth, or partially exogenous reference levels as we do. 
the dependence of developing countries on goods produced in advanced economies. Such goods have come to acquire an increasingly large proportion of "high-income" characteristics over time, including sophisticated packaging, advertising, and brand differentiation that may be described as highly visible (Stewart, 1977).

Becchetti et al. (2013) start from the premise that (i) individuals conventionally tend to compare the quality of life of their own country with that of other countries, and (ii) globalization and the development of transportation and telecommunication technologies (internet, social networks, etc.) have dramatically increased the frequency of comparisons of standard of living among different countries. ${ }^{12}$ Based on these considerations, they conduct an econometric analysis using the Eurobarometer survey, showing that life satisfaction has been increasingly negatively affected by the distance between the average national gross disposable income in the individual's own country and that of the richest country in a given geographical area. ${ }^{13}$ Tax policy implications of social comparisons between countries have been addressed by Aronsson and Johansson-Stenman (2015). Their contribution is to compare the optimal labor income tax policy implicit in a non-cooperative (Nash and Stackelberg) equilibrium with the corresponding policy implicit in a cooperative equilibrium, based on welfarist objectives.

Turning to research on tax policy and relative consumption in dynamic economies, there are only a few earlier studies available (since the bulk of literature on policy responses to positional concerns is based on static models); all of them are based on the

\footnotetext{
${ }^{12}$ Clearly, preferences are more likely to be positional once individuals have access to the media and the internet, which makes it possible for them to draw comparisons with their peers. This is especially true when it comes to evaluating one's status in relation to foreign country residents. In relation to this, Clark and Senik (2010) appeal to a number of questions that appear in the European Social Survey and find that those with no internet access (23\% of the sample) attach less importance to income comparisons. Those who spend more than one hour per weekday watching TV ( $72 \%$ of the sample) compare more in general, especially to "others", and city-dwellers (60\% of the sample) compare more, especially to "friends".

${ }^{13}$ The authors consider that countries, and not just groups of peers, may be reference groups. When doing so, they control for various types of standard reference group effects. Their findings provide additional insights on the Easterlin paradox. In fact, under the extreme case in which only relative and not absolute income matters, an equiproportional increase in individual economic wellbeing leaves individual life satisfaction unaffected. Their results imply that life satisfaction may even fall if this event is paralleled by a higher increase in per capita income of peer countries.
} 
welfarist approach to optimal taxation, and none of them considers the possibility that individuals/households are positional in terms of their wealth. Ljunqvist and Uhlig (2000) analyze optimal labor income taxation in a dynamic representativeagent model and assume that a catching-up-with-the-Joneses motive characterizes the consumer preference for relative consumption. Their work was later extended by Aronsson and Johansson-Stenman (2010, 2014), who examine optimal nonlinear taxation of labor income and capital income in overlapping-generations economies with heterogeneous agents and asymmetric information; the former study focuses on the keeping-up-with-the-Joneses motive for relative consumption, while the latter addresses the keeping-up and catching-up motives simultaneously. One result of bearing for the analysis carried out below is that, if the income tax is optimal, and if the degree of consumption positionality is constant over time, capital income taxes will play no role in the correction for positional consumption externalities.

The important research objective of the present paper is to study the distortive effects of positional preferences, as highlighted in the introduction. Few other papers address this issue as we do. Alonso-Carrera et al. (2006) consider an $A k$ model (like us) in which habit-forming households exhibit positional preferences for consumption, and examine the interaction between relative consumption and habits. The present paper analyzes the simultaneous implications of positional preferences for consumption and wealth, with exogenous labor supply. ${ }^{14}$ A study more closely related to ours is Ghosh and Wendner (2018), which examines a functionally specified framework with wealth-dependent preferences. Theirs, like ours, is an endogenous growth model with wealth externalities ${ }^{15}$, but they do not consider the general framework analyzed here. Our study differs from Ghosh and Wendner (2018) in four important ways. (i) Their paper does not focus on the distortionary nature of

\footnotetext{
${ }^{14}$ Without wealth-dependent preferences, earlier studies (for instance, Fisher and Hof (2000), Liu and Turnovsky (2005)) argue that positional preferences have no impact on the steady state equilibrium (and, therefore, do not have a distortionary effect) once labor supply is exogenous. If, additionally, utility is wealth-dependent, as in our paper, then distortionarity is possibly introduced.

${ }^{15}$ The framework of Nakamoto (2009) is similar to Ghosh and Wendner (2018), but he, however, considers a neoclassical growth model and does not have wealth externalities in his set-up.
} 
positional preferences and does not deal with non-optimal economic growth rates. The present paper explicates these issues. (ii) While their study considers a social planner's welfare function, the present paper goes further by examining both welfarist and paternalist welfare functions, as discussed above. (iii) In their paper, all social comparisons are local in nature, such that the reference levels for consumption and wealth are exclusively determined by the home economy. Our study allows for consumption and wealth comparisons with other countries (the rest of the world). (iv) Finally, their paper considers utility functions in explicit form, whereas our study develops an analysis for fully general utility functions.

In the next section, we develop the model and derive the optimality conditions for both a welfarist and a paternalist government.

\section{The Model}

We consider a dynamic general equilibrium model of a closed economy that allows for fully endogenous growth. Endogenous growth stems from constant returns to capital ( $A k$ model). Time is considered to be continuous. There is a large number of households and firms, the respective number of which we normalize to unity. Households are homogeneous and exhibit positional preferences. They derive utility not only from own consumption and own wealth (as in Weber (1930), Pigou (1941), Markowitz (1952), Kurz (1968), Zou (1994; 1995), Kaplow (2009), Nakamoto (2009), Kumhof et al. (2015), and Rehme (2017), among others), but also from own consumption relative to some consumption reference level and from own wealth relative to some wealth reference level (cf., among others, Corneo and Jeanne (1997; 2001), Fisher and Hof (2000; 2005), Futagami and Shibata (1998), Pham (2005)). 


\subsection{Technology}

A homogeneous output, $y$, is produced by capital according to the linear technology (Rebelo (1991)):

$$
y=A k, \quad A>0
$$

where $y$ is gross production per capita, and $k$ is capital per capita. The depreciation rate of capital is $\delta \in[0,1]$. We assume $(A-\delta) \geq \rho$ to ensure nonnegative endogenous growth. Moreover, there is no population growth.

\subsection{Preferences}

The representative household has preferences for consumption $c$, relative consumption $\Delta_{c} \equiv c-\bar{c}$, wealth $k$, and relative wealth $\Delta_{k} \equiv k-\bar{k}$. Relative consumption is given by individual consumption relative to some consumption reference level $\bar{c}$, and relative wealth is given by individual wealth relative to some wealth reference level $\bar{k}$. Both reference levels $(\bar{c}, \bar{k})$ are exogenous from the point of view of an individual household. ${ }^{16}$

The consumption and wealth reference levels are determined by two factors. The first factor is mean consumption, $\bar{c}^{h}$, and mean wealth, $\bar{k}^{h}$, in the home (domestic) economy (indicated by superscript $h$ ). As households are homogeneous, mean consumption and mean wealth represent natural determinants for the reference levels. Importantly, these determinants are endogenous from the point of view of the government (social planner). The second factor represents the consumption and wealth, respectively, abroad: $\bar{c}^{f}$ and $\bar{k}^{f}$, which are exogenous to the domestic government. These international comparisons might be driven by interaction via social media, such as Facebook and Twitter, or by television broadcasting. ${ }^{17}$ We

\footnotetext{
${ }^{16}$ All of the literature takes the reference levels to be exogenous for individual households. Exogeneity of the reference levels might be motivated by the fact that an individual household has a negligible impact on them. Alternatively, households might not be aware of other households' saving- and consumption decisions, thus, exogeneity might be the result of informational limitations on the side of individual households.

${ }^{17}$ As highlighted in Section 2, globalization through technological advancements (via TV, internet, social media, etc.) has led to awareness about living conditions of people in different countries, and that has had significant impact on individual well-being, implying that an individual's refer-
} 
begin by analyzing a one-country version of the model, where the foreign reference measures are fully exogenous, and extend the analysis to a two-country setting in Section 5 in which the foreign reference measures are endogenous (albeit treated as exogenous by each national policy maker).

In what follows, we specify relative consumption $\Delta_{c}$ and relative wealth $\Delta_{k}$ as

$$
\begin{aligned}
& \Delta_{c} \equiv c-\bar{c}, \quad \bar{c}=\alpha^{h} \bar{c}^{h}+\alpha^{f} \bar{c}^{f}, \quad \alpha^{h}, \alpha^{f} \in[0,1], \alpha^{h}+\alpha^{f}=1, \\
& \Delta_{k} \equiv k-\bar{k}, \quad \bar{k}=\beta^{h} \bar{k}^{h}+\beta^{f} \bar{k}^{f}, \quad \beta^{h}, \beta^{f} \in[0,1], \beta^{h}+\beta^{f}=1 .
\end{aligned}
$$

Parameters $\alpha^{i}$ and $\beta^{i}, i \in\{h, f\}$ determine the importance of the explained (endogenous) versus not explained (exogenous) parts of the positional reference levels. The standard case of fully endogenous mean value comparisons at the national level is implied by $\alpha^{h}=1, \alpha^{f}=0$ and $\beta^{h}=1, \beta^{f}=0 .{ }^{18}$ One way to think about the composition of the aggregate reference level is in terms of openness or closedness of a country with respect to international flows of goods, and information. In a country that is closed in terms of international trade or in which information (e.g., media control by the government or restricted internet access) or the freedom of international movement is restricted, $\left(\alpha^{f}, \beta^{f}\right)$ might be low relative to $\left(\alpha^{h}, \beta^{h}\right)$. The opposite occurs in a country that is open or unrestricted in the above-mentioned respects.

In this paper, both relative consumption and relative wealth enter the utility function. The instantaneous utility function is given by:

$$
u\left(c, \Delta_{c}, k, \Delta_{k}\right)
$$

For the given $A k$ technology, we may interpret the concern for relative wealth also as a concern for relative income $\left(A k-A \bar{k}=A \Delta_{k}\right)$, as this gives rise to the same general instantaneous utility function (4).

ence consumption is increasingly determined by consumption levels of people in other countries. (See Becchetti et al. (2013), Aronsson and Johansson-Stenman (2015), and also Clark and Senik (2010)).

${ }^{18} \mathrm{It}$ is important to note that the reference levels, as specified above, are flow variables. Alternatively, one could have specified them as stocks building up over time (as in Carroll et al. (1997)). However, as demonstrated by Turnovsky and Monteiro (2007), the stock- and flow specifications are equivalent (in terms of the qualitative results) along a balanced growth path. 
In our framework, labor supply is exogenous. That is why labor/leisure is not an argument in the instantaneous utility function. The consequences of endogenous labor supply for relative consumption concerns are well known from earlier studies. ${ }^{19}$ Instead, we focus on the intertemporal distortions that positional preferences might bring about.

In the standard model, $u_{c}\left(c, \Delta_{c}, k, \Delta_{k}\right)>0$, and $u_{i}\left(c, \Delta_{c}, k, \Delta_{k}\right)=0$ for some $i \in$ $\left\{\Delta_{c}, k, \Delta_{k}\right\}$, where a subscript to the utility function refers to the partial derivative, i.e., $u_{c}(.) \equiv \partial u(.) / \partial c$ and similarly for the other arguments. If $u_{\Delta_{c}}\left(c, \Delta_{c}, k, \Delta_{k}\right)>$ 0 , preferences exhibit positional concerns for consumption. For a given other's consumption level (reference level), a rise in own consumption raises utility via the increase in relative consumption. If $u_{k}\left(c, \Delta_{c}, k, \Delta_{k}\right)>0$, households derive utility not only from consumption, but also from wealth (as in Weber (1930), Pigou (1941), Markowitz (1952), Kurz (1968), Zou (1994; 1995), Kaplow (2009), Nakamoto (2009), Kumhof et al. (2015), and Rehme (2017), among others)). Finally, if $u_{\Delta_{k}}\left(c, \Delta_{c}, k, \Delta_{k}\right)>0$, preferences exhibit positional concerns for wealth. For a given wealth reference level, a rise in own wealth raises relative wealth, thereby it raises own utility. The time index $t$ is suppressed, unless necessary, to simplify the notation.

Throughout, we assume that the instantaneous utility function (4) is strictly quasiconcave, twice continuously differentiable, strictly increasing in $c$ and weakly increasing in all other arguments.

The intertemporal utility function, $U$, as viewed from date $t=0$, is given by:

$$
U=\int_{t=0}^{\infty} u\left(c, \Delta_{c}, k, \Delta_{k}\right) e^{-\rho t} d t, \quad \rho>0,
$$

where $\rho$ is the household's constant pure rate of time preference.

\footnotetext{
${ }^{19}$ See, among others, Aronsson and Johansson-Stenman (2008, 2010), Liu and Turnovsky (2005), Turnovsky and Monteiro (2007).
} 


\subsection{Market equilibrium}

Let the superscript $m$ indicate a market (decentralized) equilibrium. Households choose a consumption stream so as to maximize intertemporal utility (5) subject to:

$$
\begin{aligned}
& \dot{k}^{m}=y^{m}-c^{m}-\delta k^{m}=(A-\delta) k^{m}-c^{m}, \\
& k_{0}^{m} \text { given, } \\
& \bar{c}^{m}, \bar{k}^{m} \quad \text { exogenous }, \\
& \lim _{t \rightarrow \infty} \mu_{t}^{m} k_{t}^{m} e^{-\rho t}=0 .
\end{aligned}
$$

Differential equation (6) reflects the flow budget constraint of the representative household. Notice that (6) and (7) hold for both the market framework and a social optimum (as discussed below). Restriction (8) reflects the fact that individual households consider the positionality reference levels as exogenous. Finally, (9) is the transversality condition.

For the market economy, the current value Hamiltonian is given by:

$$
H^{m}\left(c^{m}, \Delta_{c}^{m}, k^{m}, \Delta_{k}^{m}, \mu^{m}\right)=u\left(c^{m}, \Delta_{c}^{m}, k^{m}, \Delta_{k}^{m}\right)+\mu^{m}\left[(A-\delta) k^{m}-c^{m}\right],
$$

where the costate variable $\mu^{m}$ represents the shadow price of capital. An interior solution implies the following first-order conditions:

$$
\begin{aligned}
& \mu^{m}=u_{c}\left(c^{m}, \Delta_{c}^{m}, k^{m}, \Delta_{k}^{m}\right)+u_{\Delta_{c}}\left(c^{m}, \Delta_{c}^{m}, k^{m}, \Delta_{k}^{m}\right), \\
& \frac{\dot{\mu}^{m}}{\mu^{m}}=-[(A-\delta)-\rho]-\frac{u_{k}\left(c^{m}, \Delta_{c}^{m}, k^{m}, \Delta_{k}^{m}\right)+u_{\Delta_{k}}\left(c^{m}, \Delta_{c}^{m}, k^{m}, \Delta_{k}^{m}\right)}{u_{c}\left(c^{m}, \Delta_{c}^{m}, k^{m}, \Delta_{k}^{m}\right)+u_{\Delta_{c}}\left(c^{m}, \Delta_{c}^{m}, k^{m}, \Delta_{k}^{m}\right)},
\end{aligned}
$$

where we made use of the fact that $\partial \Delta_{c} / \partial c=\partial(c-\bar{c}) / \partial c=1$ and $\partial \Delta_{k} / \partial k=1$ from the point of view of an individual household. Equation (11) is the conventional first order condition for consumption, according to which the costate variable equals the marginal utility of consumption at each point in time. Equation (12) states that the growth rate of the costate variable equals the negative of the difference between the rate of interest and the pure rate of time preference (as in the standard model) plus an additional term that is due to the non-standard preferences. This 
additional term represents the marginal rate of substitution of capital (wealth) for consumption. For the decentralized economy, an equilibrium path is characterized by $(6),(7),(9),(11)$, and (12).

Before discussing the welfarist and paternalist governments' problems, it turns out to be most useful to introduce the concept of the marginal degree of positionality (Johansson-Stenman et al., 2002), as a measure of how status concerned or positional an individual is. Specifically, the marginal degree of positionality with respect to consumption is defined by

$$
\zeta_{c} \equiv \frac{u_{\Delta_{c}}\left(c^{m}, \Delta_{c}^{m}, k^{m}, \Delta_{k}^{m}\right)}{u_{c}\left(c^{m}, \Delta_{c}^{m}, k^{m}, \Delta_{k}^{m}\right)+u_{\Delta_{c}}\left(c^{m}, \Delta_{c}^{m}, k^{m}, \Delta_{k}^{m}\right)} .
$$

The degree of consumption positionality defines the fraction of utility gain from an additional unit of consumption stemming from a rise in relative consumption $\Delta_{c}$. A value of zero indicates no positionality at all, while a value of unity indicates that only relative (not absolute) consumption matters. Likewise, we define the marginal degree of positionality with respect to wealth by

$$
\zeta_{k} \equiv \frac{u_{\Delta_{k}}\left(c^{m}, \Delta_{c}^{m}, k^{m}, \Delta_{k}^{m}\right)}{u_{k}\left(c^{m}, \Delta_{c}^{m}, k^{m}, \Delta_{k}^{m}\right)+u_{\Delta_{k}}\left(c^{m}, \Delta_{c}^{m}, k^{m}, \Delta_{k}^{m}\right)} .
$$

These degrees of positionality will play an important role in the characterization of corrective taxation in Subsection 4.3.

\subsection{Welfarist Government}

Let the superscript $w$ indicate variables associated with a welfarist government's choice problem. A welfarist government respects individual preferences, including the concerns for relative consumption and relative wealth. Since the welfarist government aims at internalizing the positional externalities, it takes into account that $\bar{c}^{h}=c$ in and $\bar{k}^{h}=k$ in equilibrium. However, both $\bar{c}^{f}$ and $\bar{k}^{f}$ are considered exogenous. From the point of view of this government, $\Delta_{c}=c\left(1-\alpha^{h}\right)-\alpha^{f} \bar{c}^{f}$, and $\Delta_{k}=k\left(1-\beta^{h}\right)-\beta^{f} \bar{k}^{f}$.

The welfarist government chooses a consumption stream so as to maximize in- 
tertemporal utility

$$
U=\int_{t=0}^{\infty} u\left(c^{w}, \Delta_{c}^{w}, k^{w}, \Delta_{k}^{w}\right) e^{-\rho t} d t
$$

subject to

$$
\begin{aligned}
& \dot{k}^{w}=(A-\delta) k^{w}-c^{w}, \\
& k_{0}^{w} \text { given, } \\
& \bar{c}^{h}=c^{w}, \quad \bar{k}^{h}=k^{w}, \\
& \lim _{t \rightarrow \infty} \mu_{t}^{w} k_{t}^{w} e^{-\rho t}=0 .
\end{aligned}
$$

Restrictions (16) - (19) have the same interpretations as those given for the market economy. The main difference compared to the decentralized framework is the fact that the social planner takes the reference levels (18) into account.

For the welfarist government, the current value Hamiltonian is given by:

$$
H^{w}\left(c^{w}, \Delta_{c}^{w}, k^{w}, \Delta_{k}^{w}, \mu^{w}\right)=u\left(c^{w}, \Delta_{c}^{w}, k^{w}, \Delta_{k}^{w}\right)+\mu^{w}\left[(A-\delta) k^{w}-c^{w}\right] .
$$

An interior solution implies the following first-order conditions:

$$
\begin{aligned}
& \mu^{w}=u_{c}\left(c^{w}, \Delta_{c}^{w}, k^{w}, \Delta_{k}^{w}\right)+\left(1-\alpha^{h}\right) u_{\Delta_{c}}\left(c^{w}, \Delta_{c}^{w}, k^{w}, \Delta_{k}^{w}\right), \\
& \frac{\dot{\mu}^{w}}{\mu^{w}}=-[(A-\delta)-\rho]-\frac{u_{k}\left(c^{w}, \Delta_{c}^{w}, k^{w}, \Delta_{k}^{w}\right)+\left(1-\beta^{h}\right) u_{\Delta_{k}}\left(c^{w}, \Delta_{c}^{w}, k^{w}, \Delta_{k}^{w}\right)}{u_{c}\left(c^{w}, \Delta_{c}^{w}, k^{w}, \Delta_{k}^{w}\right)+\left(1-\alpha^{h}\right) u_{\Delta_{c}}\left(c^{w}, \Delta_{c}^{w}, k^{w}, \Delta_{k}^{w}\right)} .
\end{aligned}
$$

The canonical equations (21) and (22) have the same interpretations as given for the

market economy above. The differences are given by the fact that the (welfarist) government takes the "home components" of the aggregate reference levels into account when deriving the optimality conditions. In other words, the (welfarist) government takes into account that a part of consumption (saving) is wasteful in terms of social welfare due to the (negative externality generating) positional preferences. An equilibrium path is characterized by (16), (17), (19), (21), and $(22)$.

\subsection{Paternalist Government}

In this subsection, we consider a paternalist government that does not respect the individuals' concerns for relative consumption and relative wealth, although it is 
assumed to respect all other aspects of consumer preferences. Therefore, instead of forming the social objective upon the individuals's actual preferences, and then implementing a policy in order to internalize the positional externalities (as the welfarist government does), the paternalist government wants the households to behave as if these relative concerns were absent. ${ }^{20}$

It is worth to emphasize that we do not take a stand (in a normative sense) on whether a government should follow a welfarist or a paternalist optimal policy. We acknowledge that there are often good reasons to pursue a welfarist policy. In a way, it seems natural to ask why a government would not implement what each individual wants. ${ }^{21}$ There are, however, arguments in favor of a paternalist government as well. First, as we mentioned in Section 2, several authors have argued against including "anti-social" preferences, such as envy, in a social welfare function. It is, therefore, relevant to compare the conventional welfarist approach to a paternalist approach when measuring the distortions caused by relative concerns. Second, from an ethical point of view, clearly there are indisputable boundaries regarding how far individual preferences could extend, beyond which such preferences must not be considered in any social welfare function. ${ }^{22}$ In general, these limits to individual behavior are often difficult to define. An important point, though, is that regardless of the definition of such boundaries, a paternalist government need not at all be totalitarian. A paternalist government is very much compatible with a decentralized economy, in which the government intervenes through economic policies designed to create the appropriate incentives.

\footnotetext{
${ }^{20}$ That is, the government's and households' preferences differ under this criterion; see Kanbur et al. (2006) for an excellent discussion, in a survey article on non-welfarist approaches to optimal taxation.

${ }^{21}$ Also, from a "Political Economy" perspective, this seems reasonable. A democratically-elected government that wants to be re-elected would be expected to propose a policy that the majority agrees with.

${ }^{22}$ One might look back at the Rwandan genocide (which happened in 1994) soon after the then President, a military leader, was killed in a plane crash. Armed groups of Hutus (over $80 \%$ of the population) started slaughtering the minority Tutsis (about $15 \%$ of the population). Now, assuming there was widespread support among the Hutu majority for ethnic cleansing of the Tutsi minority, the social welfare function, appropriately weighted, would be expected to reflect such sentiments under the welfarist welfare criterion. It is the paternalist welfare criterion that would correct for such 'behavioral failures' of individuals in this scenario.
} 
So, in our framework, a paternalist government does not fully respect individual preferences. In particular, the paternalist government attaches no social value to changes in the individuals' utilities caused by changes in the relative consumption and relative wealth. This means that the paternalist government treats the relative consumption and relative wealth as exogenous when solving its optimization problem, even if these entities are (of course) endogenous in equilibrium. In the following, variables related to the paternalist government's choice problem are indicated by the superscript $p$.

The paternalist government chooses a consumption stream so as to maximize intertemporal utility

$$
U=\int_{t=0}^{\infty} u\left(c^{p}, \bar{\Delta}_{c}, k^{p}, \bar{\Delta}_{k}\right) e^{-\rho t} d t
$$

subject to

$$
\begin{aligned}
& \dot{k}^{p}=(A-\delta) k^{p}-c^{p}, \\
& k_{0}^{p} \text { given, } \\
& \bar{\Delta}_{c}, \bar{\Delta}_{k} \text { exogenous, } \\
& \lim _{t \rightarrow \infty} \mu_{t}^{p} k_{t}^{p} e^{-\rho t}=0 .
\end{aligned}
$$

The current value Hamiltonian can then be written as

$$
H^{p}\left(c^{p}, k^{p}, \mu^{p}\right)=u\left(c^{p}, \bar{\Delta}_{c}, k^{p}, \bar{\Delta}_{k}\right)+\mu^{p}\left[(A-\delta) k^{p}-c^{p}\right]
$$

By using that $\bar{\Delta}_{c}=\Delta_{c}^{p}=c^{p}-\bar{c}$ and $\bar{\Delta}_{k}=\Delta_{k}^{p}=k^{p}-\bar{k}$ in equilibrium (where $\bar{c}$ and $\bar{k}$ are determined according to equations (2) and (3)), we can write the first-order conditions for an interior solution as follows:

$$
\begin{aligned}
& \mu^{p}=u_{c}\left(c^{p}, \Delta_{c}^{p}, k^{p}, \Delta_{k}^{p}\right), \\
& \frac{\dot{\mu}^{p}}{\mu^{p}}=-[(A-\delta)-\rho]-\frac{u_{k}\left(c^{p}, \Delta_{c}^{p}, k^{p}, \Delta_{k}^{p}\right)}{u_{c}\left(c^{p}, \Delta_{c}^{p}, k^{p}, \Delta_{k}^{p}\right)} .
\end{aligned}
$$

The canonical equations have the same general interpretation as the ones for the welfarist government. In contrast to the welfarist government, however, the paternalist government disregards status concerns, and the canonical equations equal those we would have for an economy without positional preferences. 
It is useful to compare (30) with (22) for the extreme case where $\alpha^{h}=\beta^{h}=1$ and $\alpha^{f}=\beta^{f}=0$. This is the case where the foreign components of the reference consumption and reference wealth are totally absent, and thus the reference consumption is nothing but the mean-value of home consumption. This means that the social first-order conditions coincide for the welfarist and paternalist objectives, which can be seen if we plug in $\alpha^{h}=\beta^{h}=1$ in (22): we then obtain (30). In other words, the two types of government would make the same choice in this case, albeit for different reasons. Intuitively, this is so because here, with all individuals identical, the welfarist government would be able to fully internalize the externality that each individual imposes on other people (because there is no exogenous foreign component, which it would otherwise not be able to internalize). As the externality coincides with the marginal behavioral failure of individuals (who are identical and exhibit the same marginal degrees of positionality), the paternalist government would want to impose the same policy as the welfarist government. ${ }^{23}$

\section{Positional preferences: efficiency and distortions}

In this section, we address two cases. The first case is the special case in which households have positional preferences only with respect to consumption. We develop a necessary and sufficient condition for positional preferences to be nondistortionary and consider the type of distortion occurring when this condition is not satisfied. As an aside, we develop an existence condition for a balanced growth path and show that existence does not imply efficiency (even for our framework with exogenous labor supply). The results developed are essential for analyzing the

\footnotetext{
${ }^{23}$ As shown by Aronsson and Johansson-Stenman (2018), welfarist and paternalist governments do not in general make the same choices, even if the reference levels are fully endogenous. For instance, if the individuals were allowed to be heterogeneous, and if we continue to assume (i) mean-value comparisons and (ii) that $\alpha^{h}=\beta^{h}=1$ and $\alpha^{f}=\beta^{f}=0$, the welfarist and paternalist governments would typically make different choices. The reason is that the externality that each individual imposes on other people would, in that case, be given by the average degree of positionality, while the individual's own behavioral failure (as corrected by the paternalist government) would be given by the individual's own degree of positionality.
} 
general second case, in which households have positional preferences with respect to both consumption and wealth. In the latter framework, we show that both the type of government (welfarist versus paternalist) and the exogenous-endogenous composition of the reference levels play decisive roles for whether or not positional preferences are distortionary and if so, whether the distortion causes under- or over-saving.

\subsection{Positional concerns with respect to consumption}

In this subsection, we focus on the case: $u_{\Delta_{c}}()>$.0 , and $u_{\Delta_{k}}()=$.0 . This is the case in which households are not concerned about others' wealth levels, i.e., households are positional with respect to consumption but not with respect to wealth. However, households may still be concerned about own absolute wealth, in which case $u_{k}()>$.0 . In order to sharpen our results, we distinguish $u_{k}()=$.0 from the case $u_{k}()>$.0 in the following.

\subsubsection{No preference for wealth: $u_{k}()=$.}

We compare the equilibrium path of a market economy with those of the welfarist and paternalist governments. From (12), (22) and (30), we see that

$$
\frac{\dot{\mu}^{m}}{\mu^{m}}=\frac{\dot{\mu}^{w}}{\mu^{w}}=\frac{\dot{\mu}^{p}}{\mu^{p}}=-[(A-\delta)-\rho]
$$

that is, the growth rates of the shadow prices are identical, and constant, in all three frameworks (decentralized, welfarist-, and paternalist government). As a consequence, we have $\mu^{m}=\phi^{w} \mu^{w}=\phi^{p} \mu^{p}$, with both $\phi^{w}$ and $\phi^{p}$ being constants. The ratio of any two costate variables is constant over time. From (11), (21) and (29), we can identify

$$
\phi^{w}=\frac{u_{c}\left(c, \Delta_{c}, . . .\right)+u_{\Delta_{c}}\left(c, \Delta_{c}, . . .\right)}{u_{c}\left(c, \Delta_{c}, ., .\right)+\left(1-\alpha^{h}\right) u_{\Delta_{c}}\left(c, \Delta_{c}, . .\right)}, \quad \phi^{p}=\frac{u_{c}\left(c, \Delta_{c}, . . .\right)+u_{\Delta_{c}}\left(c, \Delta_{c}, . . .\right)}{u_{c}\left(c, \Delta_{c}, ., .\right)} .
$$

In what follows, we argue that positional preferences with respect to consumption are non-distortionary if and only if $\phi^{w}$ and $\phi^{p}$ are constant (time-invariant). 
Lemma 1. $\zeta_{c}\left(c, \Delta_{c}, .,.\right)$ is a constant function if and only if

(i) $u\left(c, \Delta_{c},\right.$. . .) is homogeneous of some degree $R<1$ in $\left(c, \Delta_{c}, . ..\right)$, and

(ii) either $u\left(c, \Delta_{c}, .,.\right)$ is (a strictly increasing monotone transformation of) a linear function, or $\dot{c} / c=\dot{c}^{f} / c^{f}$ (equivalently $c^{f}=\lambda^{c} c, \lambda^{c}>0$ constant).

Proof. See Appendix.

In the Appendix we show, in detail, that the marginal degree of positionality $\zeta_{c}\left(c, \Delta_{c}, .,.\right)$ is a constant function for all homogeneous utility functions, once $c$ is growing at the same rate as $c^{f}$ (or $u\left(c, \Delta_{c}, .,.\right)$ is a linear function or a strictly increasing monotone transformation thereof). The restriction $R<1$ is required for the marginal utility of individual consumption to decline in $c$.

Assumption $1(\mathrm{~A} 1) . \zeta_{c}\left(c, \Delta_{c}, . ..\right)$ is a constant function, that $i s, \dot{\zeta}_{c}\left(c, \Delta_{c}, .,.\right)=0$.

Lemma 1 provides the conditions under which (A1) holds. One consequence of Assumption (A1) is that the marginal rate of substitution of $\Delta_{c}$ for $c$ is constant. To simplify notation in the analysis below, we define this marginal rate of substitution between $\Delta c$ and $c$ in terms of the marginal degree of positionality by

$$
\xi_{c} \equiv \zeta_{c} /\left(1-\zeta_{c}\right)
$$

If Assumption (A1) holds, $\xi_{c}$ is constant, and $u_{\Delta_{c}}=\xi_{c} u_{c}$. Throughout, we impose the following parameter restriction

$$
1+\xi_{c}\left(1-\alpha^{h}-\lambda^{c} \alpha^{f}\right) \geq 0
$$

that ensures positivity of marginal utility of consumption when own individual consumption and the consumption reference levels increase proportionately. This restriction on the positional consumption externality asserts that either the externality augments the direct effect of own consumption, or, if it is offsetting, it is dominated by the own effect (the direct positive effect of having more consumption is not dominated by any negative effect due to positional preferences). 
Proposition $1\left(u_{\Delta_{k}}()=.u_{k}()=0.\right)$.

Consider positional preferences with respect to consumption $u_{\Delta_{c}}\left(c, \Delta_{c}, . ..\right)>0$. Assumption (A1) is a necessary and sufficient assumption for the balanced growth path of the decentralized economy to be efficient (undistorted), that is, it coincides with the one implied by either the welfarist or the paternalist government.

Assume (A1) and $\dot{c} / c=\dot{c}^{f} / c^{f}$. Then, the endogenous growth rate of consumption and capital, $g$, is given by

$$
g^{m}=g^{w}=g^{p}=\frac{(A-\delta)-\rho}{(1-R)\left[1+\xi_{c}\left(1-\alpha^{h}-\lambda^{c} \alpha^{f}\right)\right]} .
$$

Proof. Under Assumption (A1), as $\zeta_{c}\left(c, \Delta_{c}, . ..\right)$ is constant, both $\phi^{w}=1 /\left(1-\alpha^{h} \zeta_{c}\right)$ and $\phi^{p}=1 /\left(1-\zeta_{c}\right)$ - see (13), (14), (32) - are constant. Therefore, the requirement for efficiency, constancy of $\phi^{w}$ and $\phi^{p}$, is satisfied. Further details of the proof (including the derivation of the endogenous growth rate) are shown in the Appendix.

Positional consumption preferences impose a consumption externality. Proposition 1 provides a necessary and sufficient condition for the positional consumption externality to be non-distortionary: constancy of the marginal degree of positionality, $\dot{\zeta}_{c}\left(c, \Delta_{c}, .,.\right)=0$. The intuition behind this result is as follows. If the positional consumption externality, as measured by $\zeta_{c}$, is the same at each point in time, there is no incentive for the consumer to reallocate the consumption over time in order to keep up with the Joneses. Therefore, the positional consumption externality does not introduce a distortion, as in Liu and Turnovsky (2005). ${ }^{24}$ This result is robust with respect to both welfare criteria (paternalist and welfarist) and with respect to the exogenous-endogenous composition of the reference level. The result is not, however, robust with respect to having absolute wealth in the utility function. As discussed below, the positional consumption externality always introduces a distortion when $u_{k}>0, u_{\Delta_{k}}=0$, and it may not introduce a distortion when $u_{k}>0$ and $u_{\Delta_{k}}>0$.

\footnotetext{
${ }^{24} \mathrm{~A}$ homogeneity condition was also introduced by Alonso-Carrera et al. (2006). However, while their paper concentrates on habits, this paper focuses on positional preferences regarding (relative) wealth. Proposition 1, though, is essential for the discussion of preferences for wealth.
} 
The technical requirements for Assumption (A1) to hold are given by Lemma 1. An example of a utility function satisfying these requirements is given by Fisher and Heijdra (2009):

$$
u\left(c, \Delta_{c}, ., .\right)=\ln \left[\frac{(1-\alpha) c+\alpha \Delta_{c}}{1-\alpha}\right] .
$$

In fact, this is an example of a strictly increasing monotone transformation of a linear function, and $\xi_{c}=(1-\alpha) / \alpha$. An example of a utility function not generally satisfying these requirements is given by Rauscher (1997):

$$
u\left(c, \Delta_{c}, . . .\right)=\frac{c^{1-\theta}}{1-\theta}+s\left(\Delta_{c}\right), \quad \theta>0, s^{\prime}>0, s^{\prime \prime}<0 .
$$

Unless function $s\left(\Delta_{c}\right)$ is homogeneous of degree $1-\theta$, this specification does not satisfy the requirements stated in Lemma 1. If $s\left(\Delta_{c}\right)$ is not homogeneous of degree $1-\theta, u\left(c, \Delta_{c}, . ..\right)$ is not homogeneous of some degree $R$. Thus $\dot{\xi}_{c}\left(c, \Delta_{c}, . ..\right) \neq 0$, and the positional consumption externality introduces an intertemporal distortion.

The fact that there is no distortion, when (A1) is satisfied, does not mean that the positional consumption externality does not impact on consumption- and savings behavior, on the $c / k$-ratio, or on the endogenous growth rate. All of these are affected by the positional consumption externality, however, the effects are the same in the decentralized economy as in the welfarist-/paternalist optimum.

This can best be seen by considering the endogenous growth rate, as reported in Proposition 1. Notice that the growth rate is (negatively) related to the propensity to consume out of total wealth, as $c / k=(A-\delta)-g$, and savings represent the endogenous growth engine. The growth rate is sensitive with respect to the positionality parameters. In particular, the growth rate decreases in $\xi_{c}$, and it increases in $\alpha^{h}$ and $\left(\lambda^{c} \alpha^{f}\right)$. The degree of positionality is given by $\xi_{c} /\left(1+\xi_{c}\right)$ and rising in $\xi_{c}$. A higher $\xi_{c}$ (a higher $\zeta_{c}$ ) raises consumption relative to savings in order to display "status." Consequently the saving rate falls, and so does the endogenous growth rate. Next, a higher $\alpha^{h}$ or $\left(\lambda^{c} \alpha^{f}\right)$ directly impacts on $\Delta_{c}$. In particular, for a given increase in consumption, $\Delta_{c}$ grows less the higher are $\alpha^{h}$ or $\left(\lambda^{c} \alpha^{f}\right)$. This, in turn, lowers the rate of decline of the marginal utility of consumption (in equilibrium), 
as shown in the appendix (Proof of Proposition 1, Step 1). The lower elasticity of marginal utility (in absolute terms) raises the optimal growth rate, by standard arguments of growth theory. Under (A1), while the positional consumption externality has an impact on the equilibrium $(c / k, g)$, the impact is not distortionary, according to Proposition 1.

We conclude this subsection by noting that the existence of a balanced growth path does not imply that the resource allocation is efficient.

Proposition 2. Existence of a balanced growth path does not imply efficiency.

Proof. See the Appendix.

Proposition 2 reveals two important findings. First, there exist balanced growth paths for which Assumption (A1) is not satisfied. In fact, as shown in the appendix, existence of a balanced growth path requires the utility function to be of the following form:

$$
v\left(c, \Delta_{c}\right)=\Delta_{c}^{-\gamma}\left[\frac{c^{1-\theta} K^{1}+K^{2}}{1-\theta}\right]+\Psi\left(\Delta_{c}\right), \quad K^{1}, K^{2} \text { constants } .
$$

If and only if utility is of form (36), there exists a balanced growth path. This growth path, however, is efficient only under restrictions. For instance, if $K^{2} \neq 0$, utility function (36) is not homogeneous - thereby the necessary and sufficient efficiency conditions (A1) is violated. One example for which consumption positionality does not introduce a distortion is: $K^{1}=1, K^{2}=0$, and $\Psi\left(\Delta_{c}\right)$ is homogeneous of degree $(1-\gamma-\theta)$. A specific example of this case is the example above (Rauscher, 1997), with $\gamma=0, K^{1}=1, K^{2}=0$, and $\Psi\left(\Delta_{c}\right)=s\left(\Delta_{c}\right)$. For all functions $s\left(\Delta_{c}\right)$, there exists a balanced growth path. But only for $s\left(\Delta_{c}\right)$ being homogeneous of degree $(1-\theta)$, the balanced growth path is efficient.

Second, even if labor supply is exogenous, consumption positionality can introduce an intertemporal distortion. This latter result is in stark contrast to the literature analyzing consumption positionality in a neoclassical framework with decreasing returns to capital, showing that a consumption externality does not intro- 
duce any steady state distortion as long as labor supply is exogenous (although the same externality may be distortive along the transitional path). ${ }^{25}$

In the present setting, with $u_{c}>0, u_{k}=0=u_{\Delta_{k}}$, any corrective optimal tax rate will be zero as long as Assumption (A1) is satisfied. As shown below, the only purpose of corrective optimal taxation will be to ensure $\dot{\zeta}_{c}\left(c, \Delta_{c}, .,.\right)=0$.

In what follows, we show that the result of Proposition 1 is not robust with respect to preferences for absolute wealth (when, in addition, households are not wealth-positional).

\subsubsection{Preference for wealth: $u_{k}()>0,. u_{\Delta_{k}}()=$.}

In contrast to the previous subsection, here we allow households to have a preference for wealth. Households care about own wealth, $u_{k}()>$.0 , but they have no positional preference for wealth, $u_{\Delta_{k}}()=$.0 . Wealth in the form of capital is an argument in households' utility functions, as in Kaplow (2009), Kumhof et al. (2015), Kurz (1968), Markowitz (1952), Nakamoto (2009), Rehme (2017), Pigou (1941), Weber (1930), and Zou (1994; 1995), among others. They argue that the incentive for accumulating capital lies not only in maximizing long-run consumption, but also to increase wealth, which in itself adds to agents' utility. That is, individuals derive utility from the mere possession of wealth and not simply its expenditure. ${ }^{26}$ We relax this assumption in the subsequent subsection. To sharpen results, though, we distinguish preferences for absolute wealth from positional preferences for wealth (when $u_{\Delta_{k}}()>$.0 ).

\footnotetext{
${ }^{25}$ Brekke and Howarth (2002, p.142) argue that "we have established that augmenting a standard neoclassical growth model to incorporate a concern for relative consumption has no impacts on long-run economic behavior." Fisher and Hof (2000, p.249) show that the result that "relative consumption does not affect the long-run steady state...is robust with respect to the specification of the instantaneous utility function." Liu and Turnovsky (2005, p.1106) state that "[w]ith exogenous labor supply, consumption externalities, which impact through the labor-consumption tradeoff, have no channel to affect steady state output" in a framework with neoclassical production. Rauscher (1997, p.38) argues that "conspicuous consumption does not affect the long-run steady state."

${ }^{26}$ Wealth in the form of real money balances, which provide utility by facilitating transactions and reducing shopping time, was introduced directly into the utility function in Ramsey-type optimizing models (see e.g., Croushore, 1993).
} 
The steps followed here and in the next subsection resemble those of the above discussion — with the right adjustments, though. There is no change with respect to the marginal utilities of consumption, as given by (11), (21) and (29). With $u_{k}()>0,.(12),(22)$ and (30) become:

$$
\begin{aligned}
& \frac{\dot{\mu}^{m}}{\mu^{m}}=-[(A-\delta)-\rho]-\frac{u_{k}\left(c^{m}, \Delta_{c}^{m}, k^{m}, .\right)}{u_{c}\left(c^{m}, \Delta_{c}^{m}, k^{m}, .\right)+u_{\Delta_{c}}\left(c^{m}, \Delta_{c}^{m}, k^{m}, .\right)}, \\
& \frac{\dot{\mu}^{w}}{\mu^{w}}=-[(A-\delta)-\rho]-\frac{u_{k}\left(c^{w}, \Delta_{c}^{w}, k^{w}, .\right)}{u_{c}\left(c^{w}, \Delta_{c}^{w}, k^{w}, .\right)+\left(1-\alpha^{h}\right) u_{\Delta_{c}}\left(c^{w}, \Delta_{c}^{w}, k^{w}, .\right)}, \\
& \frac{\dot{\mu}^{p}}{\mu^{p}}=-[(A-\delta)-\rho]-\frac{u_{k}\left(c^{p}, \Delta_{c}^{p}, k^{p}, .\right)}{u_{c}\left(c^{p}, \Delta_{c}^{p}, k^{p}, .\right)} .
\end{aligned}
$$

Following the above arguments, for equal consumption growth rates in the decentralized economy as in the welfarist-/paternalist optimum to hold, the right hand sides of (37), (38), and (39) must coincide, which essentially requires the private and social marginal rates of substitution of wealth for consumption to be equal. More specifically, the private marginal rates of substitution of wealth for consumption, evaluated in the social optimum based on the welfarist $(w)$ and paternalist $(p)$ objective is given by

$$
M R S_{k, c}^{i}=\frac{u_{k}\left(c^{i}, \Delta_{c}^{i}, k^{i}, .\right)}{u_{c}\left(c^{i}, \Delta_{c}^{i}, k^{i}, .\right)+u_{\Delta_{c}}\left(c^{i}, \Delta_{c}^{i}, k^{i}, .\right)}, \quad i=w, p .
$$

Due to the relative concern for consumption, however, the consumers' marginal willingness to pay for wealth in terms of consumption differs from the corresponding social marginal rates of substitution between wealth and consumption, which are given as follows:

$$
\begin{aligned}
S M R S_{k, c}^{p} & =\frac{u_{k}\left(c^{p}, \Delta_{c}^{p}, k^{p}, .\right)}{u_{c}\left(c^{p}, \Delta_{c}^{p}, k^{p}, .\right)} \text { and } \\
S M R S_{k, c}^{w} & =\frac{u_{k}\left(c^{w}, \Delta_{c}^{w}, k^{w}, .\right)}{u_{c}\left(c^{w}, \Delta_{c}^{w}, k^{w}, .\right)+\left(1-\alpha^{h}\right) u_{\Delta_{c}}\left(c^{w}, \Delta_{c}^{w}, k^{w}, .\right)}
\end{aligned}
$$

from the perspective of the paternalist $(p)$ and welfarist $(w)$ government.

Considering (40) and (41), we conclude:

Proposition $3\left(u_{k}()>0,. u_{\Delta_{k}}()=0.\right)$.

Suppose households have a preference for absolute wealth, but they are not wealth 
positional. If $\alpha^{h}>0$, a positional consumption preference always introduces a distortion.

If $\alpha^{h}=0$, the positional consumption preference introduces a distortion only according to the paternalist welfare criterion but not according to the welfarist welfare criterion.

If $\alpha^{h}=1$, the distortion caused by the positional consumption preference is the same for the welfarist and paternalist welfare criterion.

Proof. The results immediately follow from comparing (40) and (41) and noting that positional concerns with respect to consumption introduce a distortion only if the private and social marginal rates of substitution of wealth for consumption differ from each other.

Proposition 3 shows that positional concerns with respect to consumption are always distortionary, once households have a preference for absolute but not for relative wealth and $\alpha^{h}>0$. This is true, independently of whether or not Assumption (A1) is satisfied. The intuition is that the private marginal rate of substitution of wealth for consumption always differs from the social one. This is so because, due to the relative concerns for consumption, the consumers' marginal willingness to pay for wealth in terms of consumption differs from the corresponding social marginal rates of substitution between wealth and consumption. Specifically, if $\alpha^{h}>0$, $M R S_{k, c}^{i}<S M R S_{k, c}^{i}, i=p, w$. As individuals give up less consumption for an additional unit of savings than would be optimal according to a welfarist/paternalist optimal plan, they over-consume.

Consequently, over-consumption relative to a welfarist/paternalist optimal plan, leads to under-saving. As savings drive the rate of growth, the private (market) growth rate of consumption, wealth, and GDP (all of which are equal for all $t$ in our framework) is lower than the optimal growth rate for either a welfarist or an paternalist government.

Comparing (40) and (41), it is easy to see that, for $\alpha^{h}<1, S M R C_{k, c}^{p}>$ 
$S M R C_{k, c}^{w}$. As a consequence, over-consumption as implied by a paternalist government is greater than over-consumption as implied by a welfarist government. In other words, the endogenous growth rates rank according to: $g^{p}>g^{w}>g^{m}$.

Proposition 3 states two special cases. First, if $\alpha^{h}=0,(40)$ and (41) coincide for the welfarist government, as all of the externality is generated abroad and considered fully exogenous by both the individual and the welfarist government. Second, if $\alpha^{h}=1$, the social marginal rates of substitution (41) coincide for the paternalist and the welfarist government, as the externality generated by domestic households (which the welfarist government aims at correcting for) equals the behavioral failure of these households that the paternalist government aims at correcting for (see Footnote 23). For these reasons, Proposition 3 gives rise to:

Corollary 1. Suppose households have a preference for absolute wealth, but they are not wealth positional. Assume (A1):

$$
\text { If } \alpha^{h}>0, g^{m}<g^{w}<g^{p} ; \quad \text { if } \alpha^{h}=0, g^{m}=g^{w}<g^{p} ; \quad \text { if } \alpha^{h}=1, g^{m}<g^{w}=g^{p} \text {. }
$$

Proof. Follows directly from Proposition 3. We consider that $M R S_{k, c}^{i}>S M R S_{k, c}^{i}$ implies over-consumption, thus, under-saving and therefore a lower than socially optimal endogenous growth rate.

Proposition 3 or Corollary 1 may seem to suggest that consumption positionality necessarily leads to over-consumption. However, this intuition is misleading, as the over-consumption result neither necessarily holds in a framework without a preference for absolute wealth, nor necessarily holds in a framework in which individuals also have a positional preference for wealth (as will be discussed below).

With a preference for absolute wealth and no positional preference for wealth, though, the market equilibrium implies over-consumption for both welfare criteria. By not taking the externality into account, households overestimate the marginal utility of consumption. That is, they have a lower marginal rate of substitution of wealth for consumption than either the welfarist or the paternalist government. 
Consequently, in light of positional preferences with respect to consumption, households over-consume. In other words, households under-save, and the endogenous growth rate in the market economy is smaller than that for a welfarist or paternalist framework.

The difference between a welfarist and a paternalist government is given by the fact that the welfarist one considers the marginal disutility from the endogenous part of reference consumption, while the paternalist one fully disregards relative consumption. In other words, the welfarist government takes into account that a part of the consumption is wasteful, due to people having positional preferences, while the paternalist government considers all over-consumption to be wasteful in terms of social welfare.

So, ceteris paribus, marginal utility of consumption is higher for the welfarist government than for the paternalist one. Consequently, the welfarist marginal rate of substitution of wealth for consumption is higher than the paternalist one. This implies over-consumption of the welfarist government relative to the paternalist one. Equivalently, the saving rate is higher for the paternalist equilibrium than for the welfarist one, implying $g^{p}>g^{w}$. The special cases discussed in Corollary 1 $\left(\alpha^{h}=0,1\right)$ follow from the special cases stated in Proposition 3.

In what follows, we show that positional concerns with respect to wealth introduce a further distortion that is capable of offsetting the distortionary effect of relative consumption under wealth dependent preferences. Moreover, we show that according to a welfarist government positional preferences may lead to one distortion (say over-consumption) while, at the same time, they lead to the opposite distortion (over-saving) according to a paternalist welfare criterion.

\subsection{Positional concerns with respect to consumption and wealth}

We now turn to the general case in which households have positional preferences not only with respect to consumption but also with respect to wealth. That is, we 
consider $u_{\Delta_{c}}>0$ and $u_{\Delta_{k}}>0$. We closely follow the argumentation developed so far.

Lemma 2. $\zeta_{k}\left(c, \Delta_{c}, k, \Delta_{k}\right)$ is a constant function if and only if (i) $u\left(c, \Delta_{c}, k, \Delta_{k}\right)$ is homogeneous of some degree $\hat{R}<1$ in $\left(k, \Delta_{k}\right)$, and (ii) either $u\left(c, \Delta_{c}, k, \Delta_{k}\right)$ is (a strictly increasing monotone transformation of) a linear function of $\left(k, \Delta_{k}\right)$, or $\dot{k} / k=\dot{k}^{f} / k^{f}$ (equivalently $k^{f}=\lambda^{k} k, \lambda^{k}>0$ constant). Proof. The proof resembles that for Lemma 1 (see the Appendix).

Assumption $2(\mathrm{~A} 2) . \zeta_{k}\left(c, \Delta_{c}, k, \Delta_{k}\right)$ is a constant function, that is, $\dot{\zeta}_{k}\left(c, \Delta_{c}, k, \Delta_{k}\right)=$ 0 .

Lemma 2 provides the conditions under which (A2) holds. One consequence of Assumption (A2) is that the marginal rate of substitution of $k$ for $\Delta_{k}$ is constant. To simplify notation in the analysis below, we define this marginal rate of substitution in terms of the marginal degree of positionality by

$$
\xi_{k} \equiv \zeta_{k} /\left(1-\zeta_{k}\right)
$$

If Assumption (A2) holds, $\xi_{k}$ is constant, and $u_{\Delta_{k}}=\xi_{k} u_{k}$. Throughout, we impose the following parameter restriction

$$
1+\xi_{k}\left(1-\beta^{h}-\lambda^{k} \beta^{f}\right) \geq 0
$$

that ensures positivity of the marginal utility of wealth when own individual wealth and the wealth reference levels increase proportionately. This restriction on the positional wealth externality asserts that either the externality augments the direct effect of own wealth, or, if it is offsetting, it is dominated by the own effect.

Assumptions (A1) and (A2) together imply that (i) $u\left(c, \Delta_{c}, k, \Delta_{k}\right)=c^{R} k^{\hat{R}} \hat{u}$, with $\hat{u} \equiv u\left(1,1-\alpha^{h}-\lambda^{c} \alpha^{f}, 1,1-\beta^{h}-\lambda^{k} \beta^{f}\right)$ constant; (ii) $\zeta_{c}, \zeta_{k}$ constant; (iii) $\xi_{c}, \xi_{k}$ constant; (iv) $u_{\Delta_{c}}=\xi_{c} u_{c}$ and $u_{\Delta_{k}}=\xi_{k} u_{k}$; and (v) $u_{k} / u_{c}=(\hat{R} / R) /(c / k)$. 
As above, let

$$
M R S_{k, c}^{i}=\frac{u_{k}\left(c^{i}, \Delta_{c}^{i}, k^{i}, \Delta_{k}^{i}\right)+u_{\Delta_{k}}\left(c^{i}, \Delta_{c}^{i}, k^{i}, \Delta_{k}^{i}\right)}{u_{c}\left(c^{i}, \Delta_{c}^{i}, k^{i}, \Delta_{k}^{i}\right)+u_{\Delta_{c}}\left(c^{i}, \Delta_{c}^{i}, k^{i}, \Delta_{k}^{i}\right)}, \quad i=w, p
$$

represent the private marginal rate of substitution between wealth and consumption, evaluated in the social optimum based on the welfarist $(w)$ and paternalist $(p)$ objective, respectively. Due to the relative concerns for consumption and wealth, however, the consumers' marginal willingness to pay for wealth in terms of consumption differs from the corresponding social marginal rates of substitution between wealth and consumption, which are now given as follows:

$$
\begin{aligned}
S M R S_{k, c}^{p} & =\frac{u_{k}\left(c^{p}, \Delta_{c}^{p}, k^{p}, \Delta_{k}^{p}\right)}{u_{c}\left(c^{p}, \Delta_{c}^{p}, k^{p}, \Delta_{k}^{p}\right)} \text { and } \\
S M R S_{k, c}^{w} & =\frac{u_{k}\left(c^{w}, \Delta_{c}^{w}, k^{w}, \Delta_{k}^{w}\right)+\left(1-\beta^{h}\right) u_{\Delta_{k}}\left(c^{w}, \Delta_{c}^{w}, k^{w}, \Delta_{k}^{w}\right)}{u_{c}\left(c^{w}, \Delta_{c}^{w}, k^{w}, \Delta_{k}^{m}\right)+\left(1-\alpha^{h}\right) u_{\Delta_{c}}\left(c^{w}, \Delta_{c}^{w}, k^{w}, \Delta_{k}^{w}\right)}
\end{aligned}
$$

from the perspective of the paternalist $(p)$ and welfarist $(w)$ government. In the following, we argue that consumption and wealth externalities do not introduce any distortion if the private and social marginal rates of substitutions are identical.

Proposition 4 (Efficiency in spite of positional consumption and wealth externalities, when $\left.u_{\Delta_{k}}()>0.\right)$.

Assume (A1), (A2) and constancy of $\Delta_{c} / c$ and $\Delta_{k} / k$.

(i) Paternalist government: If and only if $\zeta_{k}=\zeta_{c}$, the market equilibrium path is efficient (according to the paternalist welfare criterion), and positional preferences do not introduce a distortion.

(ii) Welfarist government: If and only if $\beta^{h} \zeta_{k}=\alpha^{h} \zeta_{c}$, the market equilibrium path is efficient (according to the welfarist welfare criterion), and positional preferences do not introduce a distortion.

Proof. See the Appendix.

Proposition 4 provides necessary and sufficient conditions for positional preferences not to introduce a distortion. For special cases and in different contexts 
related conditions were discussed before (see Alonso-Carrera et al., 2006; Arrow and Dasgupta, 2009; Nakamoto, 2009; Ghosh and Wendner, 2018). Proposition 4, though, is in sharp contrast to the prior literature (Nakamoto 2009), which argues that positional preferences for consumption always cause a distortion when households have a preference for wealth. The proposition offers conditions under which positional preferences do not cause a distortion in spite of the fact that households have a preference for wealth.

The intuition is the following. Under Assumption (A1), the positional consumption externality is the same at each point in time, so there is no incentive for the consumer to reallocate the consumption over time in order to keep-up-with-the-Joneses in the consumption dimension. Under (A2), the positional wealth externality is the same at each point in time. Therefore, if the assumptions underlying Proposition 4 are satisfied, the marginal willingness to pay to avoid the positional consumption externality coincides with the marginal willingness to pay to avoid the positional wealth externality, and there is no incentive to change the formation of wealth in order to keep-up in the wealth dimension. This means that the incentives facing the representative individual will coincide with those facing the planner under the assumptions of Proposition 4. In other words, the two positional externalities (or behavioral failures in the paternalist case) mirror each other. In this case, there is, of course, no need for corrective taxes, as discussed below.

The conditions for the paternalist and welfarist governments coincide if $\alpha^{h}=$ $\beta^{h}=1$, such that $\zeta_{k}=\zeta_{c}$. The intuition is that in this case, the externality generated by domestic households equals the behavioral failure of these households, as the average degree of positionality equals each individual's own degree of positionality. However, if $\alpha^{h}<1$ or $\beta^{h}<1$, the externality generated by domestic households (as viewed by the welfarist government) is smaller than the behavioral failure of these households (as viewed by the paternalist government). The paternalist government attempts to internalize the same behavioral failure regardless of whether the relative concerns are driven by domestic or foreign comparisons (or 
a combination thereof). Thus, in this case, the efficiency conditions, as stated in Proposition 4, differ between the welfarist and paternalist governments.

Corollary $2\left(u_{\Delta_{c}}()=0,. u_{\Delta_{k}}()>0.\right)$.

If preferences are positional with respect to wealth but not with respect to consumption, the market equilibrium path is always inefficient, i.e., it never coincides with a socially optimal one (regardless of whether individuals have a preference for absolute wealth or not).

The corollary follows directly from the fact that $\zeta_{k}>\zeta_{c}=0$. Preferences depend on relative wealth but not on relative consumption. As there is no counteracting positionality with respect to consumption, the positional preferences are always distortionary. Specifically, positional preferences for wealth alone imply over-saving, and the distortion is stronger in light of the paternalist welfare criterion than in light of the welfarist welfare criterion. ${ }^{27}$ Considering that over-saving implies a higher than optimal endogenous growth rate (of consumption, wealth and GDP), $g^{i}, i=m, w, p$, we conclude that $g^{m}>g^{w}>g^{p} \cdot{ }^{28}$

We conclude this subsection by analyzing the type of distortion (over-consumption or over-saving) caused by positional preferences when the assumptions in Proposition 4 are not satisfied. Interestingly, we will see that positional preferences may cause over-consumption according to one welfare criterion and, at the same time, over-saving according to the other welfare criterion. Henceforth, ceteris paribus, we may experience a higher than optimal endogenous growth rate according to one welfare criterium, while experiencing a lower than optimal endogenous growth rate according to the other welfare criterium.

Proposition 5 (Welfare criteria, and the endogenous parts of $\bar{c}$ and $\bar{k}$ ). Assume (A1), (A2) and constancy of $\Delta_{c} / c$ and $\Delta_{k} / k$. The positionality parameters give rise to four cases.

\footnotetext{
${ }^{27}$ To see this formally, set $u_{\Delta_{c}}=0$ in (45). The social marginal rate of substitution of wealth for consumption is larger for a welfarist than for a paternalist government.

${ }^{28}$ Analytic expressions for the endogenous growth rates, including their derivations, are available from the authors upon request.
} 
I. $\zeta_{k}=\zeta_{c}$ and $\alpha^{h}=\beta^{h}$. There is no distortion according to either welfare criterion.

II. $\zeta_{k}=\zeta_{c}$. There is no distortion according to the paternalist welfare criterion. There is a distortion according to the welfarist welfare criterion when $\alpha^{h} \neq \beta^{h}$. Specifically, $\alpha^{h}>\beta^{h}$ implies over-consumption; $\alpha^{h}<\beta^{h}$ implies over-saving.

III. $\zeta_{k} \neq \zeta_{c}$ and $\alpha^{h}=\beta^{h}$. There is a distortion according to both welfare criteria. Specifically, $\xi_{c}>\xi_{k}$ implies over-consumption; $\zeta_{c}<\zeta_{k}$ implies over-saving.

$I V . \zeta_{k} \neq \zeta_{c}$ and $\alpha^{h} \neq \beta^{h}$.

IV.1 Let

$$
1>\frac{\zeta_{k}}{\zeta_{c}}>\frac{\alpha^{h}}{\beta^{h}} .
$$

Then positional preferences imply over-consumption according to the paternalist welfare criterion and over-saving according to the welfarist welfare criterion.

IV.2 Let

$$
1<\frac{\zeta_{k}}{\zeta_{c}}<\frac{\alpha^{h}}{\beta^{h}} .
$$

Then positional preferences imply over-consumption according to the paternalist welfare criterion and over-saving according to the welfarist welfare criterion.

Proof. We note that a negative (positive) difference between the private marginal rate of substitution of wealth for consumption and the social marginal rate of substitution implies over-consumption (over-saving). Then, all cases follow directly from comparing the private and social marginal rates of substitution as given by (44) and (45), as well as from the formulations provided in the proof of Proposition

3.

In Case I, the conditions of Proposition 4 are satisfied. Thus consumption- and wealth externalities do not introduce any distortions.

In Case II, there is no distortion according to the paternalist government, as the behavioral failures from consuming too much (because $\zeta_{c}>0$ ) exactly compensate the behavioral failure stemming from saving too much (because $\zeta_{k}>0$ ): the wealth 
positionality exactly offsets the consumption positionality (according to Proposition 4), and the individuals act as if preferences were non-positional.

The same does not hold for the welfarist government (which considers externalities but not behavioral failures). By internalizing different amounts of the wealth and consumption externalities $\left(\alpha^{h} \neq \beta^{h}\right)$, the welfarist government's marginal rate of substitution of wealth for consumption differs from that of individual households, as well as from that of the paternalist government. If, for example, $\alpha^{h}>\beta^{h}$, the welfarist government has a higher marginal rate of substitution of wealth for consumption (by internalizing relative consumption by more than relative wealth) as compared to individual households. Therefore, individual households choose a higher consumption-to-capital ratio than a welfarist government. In other words, households over-consume relative to the welfarist government. Over-consumption then implies a lower than optimal endogenous growth rate.

In Case III, $\zeta_{k} \neq \zeta_{c}$ (with $\alpha^{h}=\beta^{h}$ ) always introduces a distortion, and the distortion is stronger according to the paternalist welfare criterion compared to the welfarist one. Clearly, $\zeta_{c}>\zeta_{k}$ implies over-consumption, as individual households are more positional with respect to consumption than with respect to wealth compared with both governments. A parallel argument applies to the case in which $\zeta_{c}<\zeta_{k}$

In Case IV, we show that, depending on the shares $\left(\alpha^{h}, \beta^{h}\right)$, positional preferences may imply over-consumption according to one welfare criterion and oversaving according to the other welfare criterion. The intuitive reason is that a paternalist government only considers the marginal degrees of positionality $\left(\zeta_{c}, \zeta_{k}\right)$, while a welfarist government only considers the effective marginal degrees of positionality $\left(\alpha^{h} \zeta_{c}, \beta^{h} \zeta_{k}\right)$. Whenever $\left(\zeta_{c}>\zeta_{k}\right)$ and $\left(\alpha^{h} \zeta_{c}<\beta^{h} \zeta_{k}\right)$, or $\left(\zeta_{c}<\zeta_{k}\right)$ and $\left(\alpha^{h} \zeta_{c}>\beta^{h} \zeta_{k}\right)$, the two welfare criteria disagree, and there is overconsumption according to one criterium but, at the same time, over-saving according to the other criterium.

Cases IV.1 and IV.2 raise serious questions regarding the (optimal) policy re- 
sponses to positional preferences. While these cases are consistent from an economic standpoint, the question is whether a government should follow a welfarist or a paternalist welfare criterion upon which to base its policy analysis. An answer to this question has to be dictated by philosophical considerations ultimately. In fact, depending on the answer to this question, a government should apply one set of optimal policies rather than another one. In particular, in the presence of positional preferences, under the conditions of Case IV.1, a paternalist government should apply a consumption tax while a welfarist government should apply a tax on capital income in order to correct for the same externalities. The reverse holds for Case IV.2.

\subsection{Tax Policy Implications}

Let us now turn to the optimal tax policy implications of the social comparisons described above. A welfarist government would like to internalize the positional externalities that the relative consumption and wealth concerns give rise to, whereas the paternalist government would like each individual to behave as if these concerns were absent. As such, the two types of government have different reasons to intervene.

To simplify the interpretation, and connect the analysis to the results presented in Proposition 4, we consider a case where Assumptions (A1) and (A2) are satisfied. Under Assumptions (A1) and (A2), the two market (behavioral) failures reduce to a single effective distortion. As such, we only need one properly designed corrective tax instrument combined with the lump-sum repayment of the tax revenue. We exemplify by considering a capital income tax policy. ${ }^{29}$ The asset accumulation equation facing each individual at any time $t$ can now be written as (if we suppress the time indicator for notational convenience)

$$
\dot{k}^{m}=(A-\delta) k^{m}(1-\tau)-c^{m}+T
$$

\footnotetext{
${ }^{29}$ We could alternatively use a wealth tax or a consumption tax, which would give optimal policy rules very similar to those in Proposition 6.
} 
where $\tau$ denotes the capital income tax and $T$ represents a lump-sum transfer (positive or negative). Since the individuals are identical by assumption, the only role of the welfarist (paternalist) government is to correct for market (behavioral) failures; therefore, since the timing of the lump-sum transfer is not important here, we assume that the government's budget constraint balances at each instant, such that

$$
\tau(A-\delta) k=T
$$

In addition to conditions (6), (7), (8), and (9), the necessary conditions characterizing the decentralized economy are given by equation (46) along with the following equations:

$$
\begin{aligned}
\mu^{m} & =u_{c}\left(c^{m}, \Delta_{c}^{m}, k^{m}, \Delta_{k}^{m}\right)+u_{\Delta_{c}}\left(c^{m}, \Delta_{c}^{m}, k^{m}, \Delta_{k}^{m}\right), \\
\frac{\dot{\mu}^{m}}{\mu^{m}} & =-[(A-\delta)(1-\tau)-\rho]-\frac{u_{k}\left(c^{m}, \Delta_{c}^{m}, k^{m}, \Delta_{k}^{m}\right)+u_{\Delta_{k}}\left(c^{m}, \Delta_{c}^{m}, k^{m}, \Delta_{k}^{m}\right)}{u_{c}\left(c^{m}, \Delta_{c}^{m}, k^{m}, \Delta_{k}^{m}\right)+u_{\Delta_{c}}\left(c^{m}, \Delta_{c}^{m}, k^{m}, \Delta_{k}^{m}\right)}(49)
\end{aligned}
$$

We follow Aronsson and Johansson-Stenman (2008, 2010, 2018) by characterizing the corrective tax policy in terms of degrees of positionality (which can be empirically estimated), which are constant under Assumptions (A1) and (A2). In our model, which distinguishes between consumption positionality and wealth positionality, we defined these degrees as follows in Section 3: $\zeta_{c}=u_{\Delta_{c}} /\left(u_{c}+u_{\Delta_{c}}\right)$ and $\zeta_{k}=u_{\Delta_{k}} /\left(u_{k}+u_{\Delta_{k}}\right)$. By using the private and social marginal rates of substitution between wealth and consumption given in equations (44) and (45), the optimal tax policy response to relative consumption and wealth concerns is summarized in Proposition 6.

Proposition 6. Suppose that Assumptions (A1) and (A2) are satisfied. If $\tau$ satisfies

$$
\tau(A-\delta)=M R S_{k, c}^{p}-S M R S_{k, c}^{p}=M R S_{k, c}^{p} \frac{\zeta_{k}-\zeta_{c}}{1-\zeta_{c}}
$$

for all $t$, then $c^{m}=c^{p}$ and $k^{m}=k^{p}$ for all $t$, such that the market economy replicates the paternalist government's preferred resource allocation. 
If $\tau$ instead satisfies

$$
\tau(A-\delta)=M R S_{k, c}^{w}-S M R S_{k, c}^{w}=M R S_{k, c}^{w} \frac{\beta^{h} \zeta_{k}-\alpha^{h} \zeta_{c}}{1-\alpha^{h} \zeta_{c}}
$$

for all $t$, then $c^{m}=c^{w}$ and $k^{m}=k^{w}$ for all $t$, such that the market economy replicates the welfarist government's preferred resource allocation.

Proof: see the Appendix.

Starting with tax policy chosen by the paternalist government, we can see that the optimal corrective tax depends on a discrepancy between $M R S_{k, c}^{p}$ and $S M R S_{k, c^{*}}^{p}$. If the private marginal rate of substitution exceeds the social marginal rate of substitution, such that $M R S_{k, c}^{p}>S M R S_{k, c}^{p}$, then $\tau>0$. The intuition is that the tendency to over-accumulate wealth (due to wealth positionality) dominates the tendency to over-consume (due to consumption positionality), in which case an uncontrolled market economy would lead to more wealth accumulation at each point in time than preferred by the paternalist government. A capital income tax based on the policy rule given in equation (50) internalizes this behavioral failure. Correspondingly, if the $M R S_{k, c}^{p}<S M R S_{k, c}^{p}$, the behavioral failure implied by consumption positionality dominates the behavioral failure implied by wealth positionality, in which case equation (50) would imply $\tau<0$.

The final term on the right hand side of equation (50), i.e., the expression after the second equality, expresses the policy rule for the capital income tax in terms of the degrees of consumption and wealth positionality. The interpretation is straightforward: we should tax capital income if the degree of wealth positionality exceeds the degree of consumption positionality, i.e., if $\zeta_{k}>\zeta_{c}$, and subsidize capital income if the degree of wealth positionality instead falls short of the degree of consumption positionality such that $\zeta_{k}<\zeta_{c}$. The intuition is that the strength of each behavioral failure is captured by the degree of positionality, and since the two behavioral failures exhibit a negative correlation, the net behavioral failure 
(captured by the difference between the two degrees of positionality) determines the sign of the corrective tax. We can also see that the corrective tax is zero for all $t$ if, and only if, $\zeta_{k}=\zeta_{c}$, in which case the two behavioral failures cancel out. In that case, the consumers would behave in exactly the same way as the paternalist government wants them to do, which corresponds to the result presented in Proposition 4 (i).

Continuing with the tax policy implemented by the welfarist government given in equation (51), the sign of the optimal capital income tax will also in this case depend on a discrepancy between the private and social marginal rates of substitution between wealth and consumption. As such, the expression after the first equality in equation (51) is interpretable in exactly the same way as the corresponding expression in equation (50). However, in the welfarist case, the discrepancy between these two marginal rates of substitution cannot be directly translated in to a difference between the two degrees of positionality. This is so because the government only internalizes the domestic component of each positional externality. In a welfarist context, we can interpret the degree of wealth positionality, $\zeta_{k}$, in terms of the marginal positional wealth externality per unit of wealth, and the government internalizes the domestic fraction, $\beta^{h}$, of this externality. Similarly, the degree of consumption positionality, $\zeta_{c}$, measures the marginal positional consumption externality per unit of consumption, and the government internalizes the domestic fraction, $\alpha^{h}$, of this externality. From the perspective of a national welfarist government, the net marginal externality is, therefore, given by $\beta^{h} \zeta_{k}-\alpha^{h} \zeta_{c}$. If this difference is positive (negative), the optimal wealth tax is positive (negative). In other words, the larger the positional wealth externality $\left(\zeta_{k}\right)$ or the larger the fraction of this externality that the government internalizes $\left(\beta^{h}\right)$, ceteris paribus, the higher will be the optimal capital income tax. Conversely, the larger the positional consumption externality $\left(\zeta_{c}\right)$ or the larger the fraction of this externality that the government internalizes $\left(\alpha^{h}\right)$, ceteris paribus, the lower will be the optimal capital income tax. Note also that the two "effective externalities" cancel out if $\beta^{h} \zeta_{k}=\alpha^{h} \zeta_{c}$, in which 
case the positional concerns do not give rise to any distortion. This corresponds to the result in Proposition 4 (ii) and implies that the corrective tax is zero.

The reason why a single tax can be used to correct for two imperfections is that (i) $c$ and $k$ exhibit a negative correlation, meaning that a single capital income tax can be used to reach the desired expression for $\dot{\mu} / \mu$, and (ii) the marginal utility of relative consumption stands in a fixed proportion, $\xi_{c}$, to the marginal utility of absolute consumption if Assumption (A1) is satisfied. The latter means that the socially optimal resource allocation will satisfy the atemporal first-order condition for consumption in the market economy, which would not be the case in a more general setting that does not rely on Assumptions (A1) and (A2). Instead, this general case typically requires two corrective taxes to reach the desired resource allocation, irrespective of whether this allocation is decided on by a welfarist or paternalist government. It is straightforward to show that a capital income tax similar to those described above (albeit adjusted for the fact that the degrees of positionality are endogenous when Assumptions (A1) and (A2) are not satisfied) together with a consumption tax (designed to induce the desired atemporal first-order condition for consumption) can be used to implement the desired social optimum.

\section{Extension to a Global Economy}

Contrary to earlier sections, which focus on a single country and treat "the rest of the economy" (the rest of the "world") as exogenous, this section extends the analysis to a global economy with two countries. In this setting, the foreign part of the reference measures for consumption and wealth, respectively, have natural interpretations in terms of the consumption and wealth of individuals in the other country. ${ }^{30}$ The purpose is to examine to what extent national policy-making, as reflected in the choices made by the national governments in the preceding sections,

\footnotetext{
${ }^{30}$ The number of countries (as long as it exceeds one) is not important for the results to be presented below. Without loss of generality, therefore, we consider the simplest possible case with only two countries.
} 
is able to internalize market and behavioral failures also on a global (multi-country) level. In other words, we shall briefly discuss whether positional consumption and wealth preferences are still distortive on a global level, despite the national governments having made their optimal choices. The benchmark is thus an optimal resource allocation from the perspective of a global social planner, whose objective is based on welfarism and paternalism, respectively, as formalized above.

With a welfarist social planner, a global social optimum can be derived by choosing consumption streams to maximize the following sum of intertemporal utilities (for $i=1,2$ and $j \neq i$ ):

$$
U=\int_{t=0}^{\infty} \sum_{\ell=1}^{2} u\left(c^{\ell}, \Delta_{c}^{\ell}, k^{\ell}, \Delta_{k}^{\ell}\right) e^{-\rho t} d t
$$

subject to

$$
\begin{aligned}
& \dot{k}^{i}=(A-\delta) k^{i}-c^{i}, \\
& k_{0}^{i}=k_{0}^{j} \text { given }, \\
& \bar{c}^{i}=\alpha^{h} c^{i}+\alpha^{f} c^{j}, \bar{k}^{i}=\beta^{h} k^{i}+\beta^{f} k^{j}, \\
& \Delta_{c}^{i}=c^{i}-\bar{c}^{i}, \quad \Delta_{k}^{i}=k^{i}-\bar{k}^{i} \\
& \lim _{t \rightarrow \infty} \mu_{t}^{i} k_{t}^{i} e^{-\rho t}=0 .
\end{aligned}
$$

Except for the country indicators, the notation is the same as before. To be able to focus on the distortions caused by positional preferences in the simplest possible way, the above decision-problem assumes that the countries are identical. This allows us to abstract from redistribution policies at the international level, which are not essential for the nature of the positional externalities involved. ${ }^{31}$ If the global social planner is paternalist, the instantaneous utility function in equation (52) is replaced by $u\left(c^{\ell}, \bar{\Delta}_{c}^{\ell}, k^{\ell}, \bar{\Delta}_{k}^{\ell}\right)$ for $\ell=1,2$, where $\bar{\Delta}_{c}^{\ell}$ and $\bar{\Delta}_{k}^{\ell}$ are treated as exogenous during optimization albeit endogenous in equilibrium (such that $\bar{\Delta}_{c}^{\ell}=\Delta_{c}^{\ell}$ and $\bar{\Delta}_{k}^{\ell}=\Delta_{k}^{\ell}$ ). Furthermore, restriction (55) is redundant in the paternalist case.

\footnotetext{
${ }^{31}$ Instead of assuming that the initial capital stocks are equal, an alternative way of deriving Proposition 7 would be to assume a redistribution policy by adding a lump-sum subsidy to each country, $T^{i}$, along with a budget constraint for the global social planner, $T^{1}=-T^{2}$.
} 
By using the approach presented in Section 4, the social optimum is characterized in Proposition 7.

Proposition 7. Based on the decision-problem (52)-(57), and irrespective of whether the global social planner is welfarist or paternalist, the global social optimum satisfies the following conditions:

$$
\begin{aligned}
\mu & =\mu^{i}=u_{c}\left(c^{i}, \Delta_{c}^{i}, k^{i}, \Delta_{k}^{i}\right) \\
\frac{\dot{\mu}}{\mu} & =-[(A-\delta)-\rho]-\frac{u_{k}\left(c^{i}, \Delta_{c}^{i}, k^{i}, \Delta_{k}^{i}\right)}{u_{c}\left(c^{i}, \Delta_{c}^{i}, k^{i}, \Delta_{k}^{i}\right)} .
\end{aligned}
$$

for $i=1,2$.

Proof: see the Appendix.

The result given in Proposition 7 arises because the two countries are identical, meaning that $c^{1}=c^{2}$ and $k^{1}=k^{2}$. Therefore, the externalities that the global welfarist planner internalizes coincide with the behavioral failures that the paternalist planner corrects for.

We can now compare the global social optimum characterized in Proposition 7 with the Nash-equilibrium allocation that would follow if (i) the policies were based on national objectives and (ii) each national social planner treats the decisionvariables of the other country as exogenous. Such an allocation would imply that each country satisfies equations (21) and (22) or equations (29) and (30), depending on whether the national decision-makers are welfarist or paternalist governments. More specifically, and in addition to (53)-(57), Nash-competition among welfarist national governments satisfies the conditions

$$
\begin{aligned}
& \mu^{i}=u_{c}\left(c^{i}, \Delta_{c}^{i}, k^{i}, \Delta_{k}^{i}\right)+\left(1-\alpha^{h}\right) u_{\Delta_{c}}\left(c^{i}, \Delta_{c}^{i}, k^{i}, \Delta_{k}^{i}\right), \\
& \frac{\dot{\mu}^{i}}{\mu^{i}}=-[(A-\delta)-\rho]-\frac{u_{k}\left(c^{i}, \Delta_{c}^{i}, k^{i}, \Delta_{k}^{i}\right)+\left(1-\beta^{h}\right) u_{\Delta_{k}}\left(c^{i}, \Delta_{c}^{i}, k^{i}, \Delta_{k}^{i}\right)}{u_{c}\left(c^{i}, \Delta_{c}^{i}, k^{i}, \Delta_{k}^{i}\right)+\left(1-\alpha^{h}\right) u_{\Delta_{c}}\left(c^{i}, \Delta_{c}^{i}, k^{i}, \Delta_{k}^{i}\right)},
\end{aligned}
$$

whereas Nash-competition among paternalist national governments satisfies 


$$
\begin{aligned}
\mu^{i} & =u_{c}\left(c^{i}, \Delta_{c}^{i}, k^{i}, \Delta_{k}^{i}\right) \\
\frac{\dot{\mu}^{i}}{\mu^{i}} & =-[(A-\delta)-\rho]-\frac{u_{k}\left(c^{i}, \Delta_{c}^{i}, k^{i}, \Delta_{k}^{i}\right)}{u_{c}\left(c^{i}, \Delta_{c}^{i}, k^{i}, \Delta_{k}^{i}\right)}
\end{aligned}
$$

for $i=1,2$. Since the two countries are identical by assumption, both equations (60) and (61) and equations (62) and (63) imply $c^{1}=c^{2}$ and $k^{1}=k^{2}$ (even if the levels typically differ between the two resource allocations). The following corollary is a direct consequence of Proposition 5 and equations (60)-(63):

Corollary 3. Within the given framework, Nash-competing paternalist governments would always implement the global social optimum. Under Assumptions (A1) and (A2), Nash-competing welfarist governments would implement the global social optimum if, and only if, $\left(1-\zeta_{c} \alpha^{h}\right) /\left(1-\zeta_{c}\right)=\left(1-\zeta_{k} \beta^{h}\right) /\left(1-\zeta_{k}\right)$.

Therefore, whereas the choices made by Nash-competing paternalist national governments lead to a global social optimum, Nash-competition among welfarist national governments does not in general lead to a globally optimal resource allocation. The intuition is, of course, that the behavioral failure of each individual, which the paternalist government wants to correct for, is the same regardless of whether the social comparisons have an international dimension. In the welfarist case, on the other hand, the national governments only internalize the domestic parts of the two externalities, implying that the resource allocation implemented by Nash-competing welfarist governments will typically differ from the allocation preferred by a global social planner. If the extent to which the relative concerns are based on domestic comparisons is the same for consumption and wealth such that $\alpha^{h}=\beta^{h}<1$, then Nash-competing welfarist governments would implement the global social optimum if, and only if, the degrees of consumption positionality and wealth positionality are equal. A more distinct special case arises if $\alpha^{h}=\beta^{h}=1$, in which the welfarist allocation coincides with the global social optimum. Since empirical research on relative concerns and well-being has started to discern social reference groups, as 
well as estimated degrees of positionality for consumption and for certain aspects of wealth (or related durable goods), an interesting and feasible topic for future research would be to examine whether these conditions are close to being satisfied.

\section{Conclusions}

In the context of an endogenous growth model with exogenous labor supply, and in the presence of positional preferences for wealth in addition to consumption, this paper addresses the important research question as to whether positional preferences are distortionary, and if so, whether they lead to over-consumption or over-saving. The paper shows that the answer depends on three main factors: the characteristics of the utility function (the constancy of the degree of positionality of consumption and/or wealth); the extent to which the relative concerns reflect comparisons with people in other countries; and the nature of the welfare criterion (welfarist or paternalist). Based on the same two welfare criteria, we also address corrective tax policy in order to internalize the welfare costs of relative consumption and wealth concerns.

When households are positional, they compare their own consumption and wealth to reference points. These reference points are in part determined by the equilibrium in the home economy (e.g., the mean consumption in the domestic economy), and also in part by choices made in other countries which the domestic government is assumed to treat as exogenous. It turns out that this "endogenousexogenous composition" of reference levels plays a key role for whether positional preferences imply over-consumption or over-saving according to a welfarist government. This is because individual households consider reference levels as exogenous, while a welfarist government internalizes the endogenous parts of the reference levels. Depending on the relative size of the foreign component in each reference measure, a welfarist government can have a higher- or a lower marginal rate of substitution of wealth for consumption than an individual household.

In contrast to a neoclassical growth framework, typically considered in the 
literature, we show in our endogenous growth set-up that positional preferences may introduce intertemporal distortions in spite of the labor supply being exogenous. Had labor supply been determined endogenously, intra-temporal distortions would be present in addition to the intertemporal distortions analyzed here. For instance, when households exhibit a preference for absolute wealth (but not a positional preference for wealth), then consumption positionality always introduces over-consumption (under both a welfarist and a paternalist government), and this we believe is an important contribution to the literature. If, in addition, households also have a preference for relative wealth, i.e., they are wealth-positional, then some conditions need to be satisfied for positional preferences in such a framework to be non-distortionary, and we provide those necessary and sufficient conditions in our paper.

Three of our results stand out, in particular. First, when the endogenousexogenous composition is the same for both the consumption and the wealth reference levels, the distortion of positional preferences is typically stronger under a paternalist government than under a welfarist one. This is because the former completely disregards any positional preferences in its social welfare function, while the latter only internalizes the domestic part of the positional externalities. As a consequence, a paternalist government typically implements a higher capital income tax than a welfarist government in order to correct for the welfare costs of relative consumption and wealth concerns. Second, we identify the (apparently contradictory, yet economically logical) cases for which distortions caused by positional preferences imply over-consumption according to the welfarist criterion, while implying over-saving according to the paternalist criterion. These cases involve restrictions on the degrees of positionality as well as on the endogenous-exogenous compositions of the reference levels. Third, by extending the analyses to a global economy where the foreign reference levels (for consumption and wealth) are endogenous, and if we abstract from distributional concerns, we show that Nash-competing paternalist governments implement the global social optimum, whereas Nash-competing 
welfarist governments do not.

Several further research questions, not addressed in this study, are potentially significant and interesting. First, if households are heterogeneous in terms of wealth, skills, or preferences, what can be said about the simultaneous distortions created by consumption and wealth positionality, and what would be the optimal tax policy implications thereof? How would the corrective motives for taxation analyzed above interact with the redistributive elements of the tax system? Second, empirical research is required to provide further evidence about the degrees of positionality and to produce estimates for both the home country's and the foreign country's importance in the formation of an individual's reference levels of consumption and wealth. These estimates will typically vary between individuals and between countries. As a consequence, optimal corrective policies are likely to vary across countries as well.

\section{Appendix}

\section{Proof of Lemma 1}

According to definition $(13), \zeta_{c}\left(c, \Delta_{c}, .,.\right)$ is a constant function if and only if the marginal degree of substitution of $c$ for $\Delta_{c}$ is constant for all $\left(c, \Delta_{c}, .,.\right)$. Homogeneity (homotheticity) requirement (i) ensures that this marginal degree of substitution is a function of the ratio $\Delta_{c} / c$. The restriction of the degree of homogeneity to $R<1$ ensures declining marginal utility of individual consumption.

There are two possible cases. First, $u\left(c, \Delta_{c}, .,.\right)$ is a strictly increasing monotone transformation of a linear function. In this case (in addition of $u\left(c, \Delta_{c}, .,.\right)$ being homothetic), the marginal degree of substitution is a constant (independent of the ratio $\left.\Delta_{c} / c\right)$. Obviously, in this case the marginal degree of substitution of $c$ for $\Delta_{c}$ is constant for all $\left(c, \Delta_{c}, .,.\right)$.

Second, $\dot{c} / c=\dot{c}^{f} / c^{f}$ (equivalently $c^{f}=\lambda^{c} c, \lambda^{c}>0$ constant). By homogeneity, the marginal degree of substitution of $c$ for $\Delta_{c}$ is a function of the ratio $\Delta_{c} / c$. If $\dot{c} / c=\dot{c}^{f} / c^{f}$, then $\dot{c} / c=\dot{\Delta}_{c} / \Delta_{c}$, as can easily be calculated from (2). In equilibrium, $\Delta_{c}=c-\alpha^{h} c-\alpha^{f} c^{f}=c\left(1-\alpha^{h}\right)-\alpha^{f} \lambda^{c} c$, where the right-hand-side formulation 
holds true if and only if $\dot{c} / c=\dot{c}^{f} / c^{f}$. Under this assumption, $\Delta_{c}=c\left[\left(1-\alpha^{h}\right)-\alpha^{f} \lambda^{c}\right]$. Log-differentiation, under this assumption, yields $\dot{c} / c=\dot{\Delta}_{c} / \Delta_{c}$. Consequently, the ratio $\Delta_{c} / c$ is a constant.

\section{Proof of Proposition 1}

We consider $k_{0}^{m}=k_{0}^{w}=k_{0}^{p}$. It is easy to show that - as in the standard $A k$ framework - the dynamic system is one-dimensional, and the steady state is unstable. That is, there is no transitional dynamics, and consumption and capital grow at their balanced growth rates "from the beginning." This argument follows standard textbook reasoning.

Step 1. Consumption and capital grow at the same rate. We show that the endogenous growth rate of the market economy equals that of the (welfarist- and paternalist) government: $g^{m}=g^{w}=g^{p}$.

Given that consumption and capital grow at their balanced growth rates "from the beginning," $\dot{k} / k$ is constant, and (6) requires $c$ to grow at the same rate as $k$. Let $g$ denote this growth rate. In the following we show that $g=\dot{c} / c$ is the same for the decentralized economy as for the welfarist-/paternalist government. As a matter of fact, although $\mu^{m} \neq \mu^{w} \neq \mu^{p}$, from (11), (21), (29) it follows that the growth rates of the costate variables (being the same) all equal: $\dot{\mu}^{m} / \mu^{m}=\dot{\mu}^{w} / \mu^{w}=\dot{\mu}^{p} / \mu^{p}=\dot{u}_{c} / u_{c}$. This is due to Assumption (A1), according to which $u_{\Delta_{c}}=\xi_{c} u_{c}$, where $\xi_{c} \equiv \zeta_{c} /\left(1-\zeta_{c}\right)$ is a constant. This implies in particular that the growth rate $\dot{u}_{c} / u_{c}$ is independent of whether or not $\bar{c}$ or $\bar{\Delta}_{c}$ is exogenous to the decision maker. That is, for the market economy as well as for both governments,

$$
\frac{\dot{\mu}}{\mu}=\frac{\dot{u}_{c}}{u_{c}}=\frac{u_{c c} c}{u_{c}} \frac{\dot{c}}{c}+\frac{u_{c \Delta_{c}} c}{u_{c}} \frac{\dot{\Delta}_{c}}{c} .
$$

Next, we observe that (i) $\dot{\Delta}_{c} / c=\left(1-\alpha^{h}-\lambda^{c} \alpha^{f}\right) \dot{c} / c$; (ii) $u_{c \Delta_{c}}=u_{\Delta_{c} c}=\partial u_{\Delta_{c}} / \partial c=$ $\partial \xi_{c} u_{c} / \partial c=\xi_{c} u_{c c}$; (iii) by homogeneity of degree $R, u_{c c} c / u_{c}=-(1-R)$. Consider- 
ing (i) to (iii) together with (31) yields

$$
g^{i}=\left(\frac{\dot{c}}{c}\right)^{i}=\frac{(A-\delta)-\rho}{(1-R)\left[1+\xi_{c}\left(1-\alpha^{h}-\lambda^{c} \alpha^{f}\right)\right]}, \quad i \in\{m, w, p\} .
$$

Step 2. As $g^{m}=g^{w}=g^{p}$ we have $c_{t}^{m}=c_{t}^{w}=c_{t}^{p}$ for all $t \geq 0$. For $t=0$, observe that $k_{0}^{m}=k_{0}^{w}=k_{0}^{p}$. From (6), (16) and (24), $c_{0}=[(A-\delta)-g] k_{0}$. As $k_{0}^{m}=k_{0}^{w}=k_{0}^{p}$, it follows that $c_{0}^{m}=c_{0}^{w}=c_{0}^{p}$. Finally, as the growth rates are identical, we also have $c_{t}^{m}=c_{t}^{w}=c_{t}^{p}$ for all $t>0$.

Step 3. The transversality conditions (TVC) are satisfied. Let $\hat{u} \equiv u\left(1,1-\alpha^{h}-\right.$ $\left.\lambda^{c} \alpha^{f}, . ..\right)$. We have $\mu^{m}=R\left(1+\xi_{c}\right) \hat{u} c^{R-1} \neq \mu^{w}=R\left(1+\xi_{c}\left(1-\alpha^{h}\right)\right) \hat{u} c^{R-1} \neq \mu^{p}=$ $R \hat{u} c^{R-1}$. Next we consider $\mu_{t}^{i}=\mu_{0}^{i} e^{-[(A-\delta)-\rho] t}, i \in\{m, w, p\}, c_{t}=c_{0} e^{g t}$, and $k_{t}=k_{0} e^{g t}$. Plugging these expressions into the respective TVC yields the following necessary and sufficient condition for the TVC (in all three frameworks) to be satisfied: $(A-\delta)>g$. This condition, however, is satisfied in all three frameworks (market, welfarist, paternalist), as $c / k=(A-\delta)-g>0$.

From steps 1 to 3 we conclude that all equilibrium paths are identical, therefore the decentralized equilibrium path is efficient (indeed optimal) according to either the welfarist or the paternalist welfare criterion.

\section{Proof of Proposition 2}

Let $v\left(c, \Delta_{c}\right) \equiv u\left(c, \Delta_{c}, .,.\right)$. Throughout we assume that $\left(c=\lambda^{c} c^{f}\right) \Leftrightarrow\left(\dot{c} / c=\dot{c}^{f} / c^{f}\right)$ is satisfied. Efficiency requires

$$
\frac{v_{\Delta_{c}}\left(c, \Delta_{c}\right)}{v_{c}\left(c, \Delta_{c}\right)}=\text { constant }
$$

and existence of a balanced growth path requires a constant growth rate of the costate variable:

$$
\frac{\dot{\mu}}{\mu}=\underbrace{\frac{v_{c c}\left(c, \Delta_{c}\right) c}{v_{c}\left(c, \Delta_{c}\right)}}_{\stackrel{!}{=} \text { constant }} \frac{\dot{c}}{c}+\underbrace{\frac{v_{c \Delta_{c}}\left(c, \Delta_{c}\right) \Delta_{c}}{v_{c}\left(c, \Delta_{c}\right)}}_{! !} \frac{\dot{\Delta}_{c}}{\Delta_{c}}=\text { constant } \text { constant. }
$$


Both $\dot{c} / c$ and $\dot{\Delta}_{c} / \Delta_{c}$ are constant on a balanced growth path. The existence condition is satisfied if both elasticities of marginal utility are constant as well.

As demonstrated in the proof of Proposition 1, efficiency condition (A1) implies constancy of both elasticities of marginal utility. That is, $(\mathrm{EF}) \Rightarrow(\mathrm{EX})$. The reverse does not hold, though.

Assume (EX), and let $\theta$ and $\gamma$ denote the elasticities:

$$
\theta \equiv-\frac{v_{c c}\left(c, \Delta_{c}\right) c}{v_{c}\left(c, \Delta_{c}\right)}, \quad \gamma \equiv-\frac{v_{c \Delta_{c}}\left(c, \Delta_{c}\right) \Delta_{c}}{v_{c}\left(c, \Delta_{c}\right)} .
$$

From this information, we first derive the marginal utility of consumption. In the proceeding step, we use the result to infer the utility function.

Step 1. Marginal utility

$$
\begin{aligned}
& \frac{v_{c \Delta_{c}}\left(c, \Delta_{c}\right)}{v_{c}\left(c, \Delta_{c}\right)}=\frac{d}{d \Delta_{c}} \ln v_{c}\left(c, \Delta_{c}\right)=-\frac{\gamma}{\Delta_{c}} \\
& \Rightarrow \int \frac{d}{d \Delta_{c}} \ln v_{c}\left(c, \Delta_{c}\right) d \Delta_{c}=-\int \frac{\gamma}{\Delta_{c}} d \Delta_{c}=-\gamma \ln \Delta_{c}+\xi \\
& \Rightarrow \ln v_{c}\left(c, \Delta_{c}\right)+\hat{f}(c)=-\gamma \ln \Delta_{c}+\xi \\
& \Rightarrow \ln v_{c}\left(c, \Delta_{c}\right)=\ln \left(\Delta_{c}^{-\gamma}\right)+f(c), \quad f(c) \equiv \xi-\hat{f}(c) \\
& \Rightarrow e^{\ln v_{c}\left(c, \Delta_{c}\right)}=e^{\ln \left(\Delta_{c}^{-\gamma}\right)} e^{f(c)} \\
& \Rightarrow v_{c}\left(c, \Delta_{c}\right)=\Delta_{c}^{-\gamma} e^{f(c)}
\end{aligned}
$$

where $\xi$ and $\hat{f}(c)$ are constants of integration.

Step 2. Utility. Integrating the above with respect to $c$ yields:

$$
\begin{aligned}
& \int \frac{d}{d c} v\left(c, \Delta_{c}\right) d c=\Delta_{c}^{-\gamma} \underbrace{\int e^{f(c)} d c}_{\equiv \varphi(c)} \\
& \Rightarrow v\left(c, \Delta_{c}\right)-\Psi\left(\Delta_{c}\right)=\Delta_{c}^{-\gamma} \varphi(c) \\
& \Rightarrow v\left(c, \Delta_{c}\right)=\Delta_{c}^{-\gamma} \varphi(c)+\Psi\left(\Delta_{c}\right),
\end{aligned}
$$

where $\Psi\left(\Delta_{c}\right)$ is a constant of integration. Next, we use constancy of the elasticity of marginal utility again, to obtain an expression for $\varphi(c)$. Solving the differential 
equation, $v_{c c} c / v_{c}=\varphi_{c c} c / \varphi_{c}=\theta$, yields:

$$
\varphi(c)=\frac{c^{1-\theta} K^{1}}{1-\theta}+\hat{K}^{2}
$$

where $K^{1}$ and $\hat{K}^{2}$ are arbitrary constants of integration. Setting $\hat{K}^{2}=K^{2} /(1-\theta)$ yields (36).

\section{Proof of Proposition 4}

Consider the private and social marginal rates of substitution of wealth for consumption, (44) and (45). Considering the definitions of $\zeta_{c}$ and $\zeta_{k},(13)$ and (14), we can express the social marginal rates of substitution by:

$$
\begin{gathered}
S M R S_{k, c}^{p}=M R S_{k, c}^{p} \frac{1-\zeta_{k}}{1-\zeta_{c}} \\
S M R S_{k, c}^{w}=M R S_{k, c}^{w} \frac{1-\beta^{h} \zeta_{k}}{1-\alpha^{h} \zeta_{c}} .
\end{gathered}
$$

Hence, the differences between the private and social marginal rates of substitution are given by

$$
\begin{array}{r}
M R S_{k, c}^{p}-S M R S_{k, c}^{p}=M R S_{k, c}^{p} \frac{\zeta_{k}-\zeta_{c}}{1-\zeta_{c}} \\
M R S_{k, c}^{w}-S M R S_{k, c}^{w}=M R S_{k, c}^{w} \frac{\beta^{h} \zeta_{k}-\alpha^{h} \zeta_{c}}{1-\alpha^{h} \zeta_{c}} .
\end{array}
$$

Those differences equal zero (no distortion), when $\zeta_{k}=\zeta_{c}$ (paternalist government) or $\beta^{h} \zeta_{k}=\alpha^{h} \zeta_{c}$ (welfarist government), which completes the proof.

\section{Proof of Proposition 6}

With the taxes described in (50) and (51), which are based on Assumptions (A1) and (A2), it follows that the market equilibrium $(m)$ as well as the welfarist $(w)$ and paternalist $(p)$ social optima all satisfy

$$
\frac{\dot{\mu}}{\mu}=-[(A-\delta)(1-\tau)-\rho]-\frac{u_{k}\left(c, \Delta_{c}, k, \Delta_{k}\right)}{u_{c}\left(c, \Delta_{c}, k, \Delta_{k}\right)} .
$$

Therefore, $\mu^{m}=\phi^{w} \mu^{w}=\phi^{p} \mu^{p}$, where $\phi^{w}$ and $\phi^{p}$ are constants. Based on Assumption $(\mathrm{A} 1)$, we can calculate $\phi^{w}=\left(1+\xi_{c}\right) /\left(1+\left(1-\alpha^{h}\right) \xi_{c}\right)$ and $\phi^{p}=\left(1+\xi_{c}\right)$. By 
using the first-order condition for consumption in the market economy,

$u_{c}\left(c, \Delta_{c}, k, \Delta_{k}\right)\left(1+\xi_{c}\right)=\mu^{m}$, we can see that this condition coincides with the first-order condition for consumption in the welfarist optimum if the corrective tax is given by equation (51), and coincides with that of the paternalist optimum if the corrective tax is instead given by equation (50). Consequently, since the three regimes satisfy the same type of equation of motion and initial condition for the capital stock as well as the same type of transversality condition, it follows that the market economy replicates the welfarist optimum if the corrective tax is given by equation (51), and the paternalist optimum if the corrective tax is given by equation (50).

\section{Proof of Proposition 7}

With a paternalist planner at the global level, a social optimum satisfies the following first-order conditions:

$$
\begin{gathered}
u_{c}\left(c^{i}, \Delta_{c}^{i}, k^{i}, \Delta_{k}^{i}\right)=\mu^{i} \\
\dot{\mu}^{i}=-\mu^{i}[(A-\delta)-\rho]-u_{k}\left(c^{i}, \Delta_{c}^{i}, k^{i}, \Delta_{k}^{i}\right),
\end{gathered}
$$

whereas a welfarist planner satisfies the corresponding conditions

$$
\begin{gathered}
u_{c}\left(c^{i}, \Delta_{c}^{i}, k^{i}, \Delta_{k}^{i}\right)+\left(1-\alpha^{h}\right) u_{\Delta_{c}}\left(c^{i}, \Delta_{c}^{i}, k^{i}, \Delta_{k}^{i}\right)-\alpha^{f} u_{\Delta_{c}}\left(c^{j}, \Delta_{c}^{j}, k^{j}, \Delta_{k}^{j}\right) \\
\dot{\mu}^{i}=-\mu^{i}[(A-\delta)-\rho]-\left(1-\beta^{h}\right) u_{k}\left(c^{i}, \Delta_{c}^{i}, k^{i}, \Delta_{k}^{i}\right)-\beta^{f} u_{k}\left(c^{j}, \Delta_{c}^{j}, k^{j}, \Delta_{k}^{j}\right)
\end{gathered}
$$

for $i=1,2$ and $j \neq i$. Since the two countries are identical, and $\alpha^{h}+\alpha^{f}=$ $\beta^{h}+\beta^{f}=1$, equations (67)-(68) and equations (69)-(70) are equivalent. As such, and irrespective of whether the global social planner is welfarist or paternalist, the optimal resource allocation satisfies equations (58)-(59) in Proposition 7. 


\section{References}

[1] Abel, A.B. (2005), Optimal Taxation when Consumers have Endogenous Benchmark Levels of Consumption, Review of Economic Studies 72, 21-42.

[2] Alonso-Carrera, J., J. Caballé, X. Raurich (2006), Welfare Implications of the Interaction between Habits and Consumption Externalities, International Economic Review 47, 557-571.

[3] Andersen, Torben M., Bengt Holmström, Seppo Honkapohja, Sixten Korkman, Hans Tson Söderström, Juhana Vartiainen (2007), The Nordic Model Embracing Globalization and Sharing Risks, Research Institute of the Finish Economy (ETLA), Taloustieto Oy, Helsinki.

[4] Aronsson, T., O. Johansson-Stenman (2008), When the Joneses' Consumption Hurts: Optimal Public Good Provision and Nonlinear Income Taxation, Journal of Public Economics 92, 986-997.

[5] Aronsson, T., O, Johansson-Stenman (2010), Positional Concerns in an OLG Model: Optimal Labor and Capital Income Taxation, International Economic Review 51, 1071-1095.

[6] Aronsson, T., O, Johansson-Stenman (2014), When Samuelson met Veblen Abroad: National and Global Public Good Provision When Social Comparisons Matter, Economica 81, 224-243.

[7] Aronsson and Johansson-Stenman (2015). Keeping up with the Joneses, the Smiths and the Tanakas: On international tax coordination and social comparisons, Journal of Public Economics 131, 71-86

[8] Aronsson, T., O. Johansson-Stenman (2018), Paternalism against Veblen: Optimal Taxation and Non-respected Preferences for Social Comparisons, American Economic Journal: Economic Policy (10), 39-76. 
[9] Aronsson, T., O. Johansson-Stenman, R. Wendner (2018), Redistribution through Charity and Optimal Taxation when People are Concerned with Social Status. Unpublished Manuscript.

[10] Arrow, K.J., P.S. Dasgupta (2009), Conspicuous Consumption, Inconspicuous Leisure, Economic Journal 119, F497-F516.

[11] Arrow, K.J., M. Kurz (1970), Public Investment, the Rate of Return, and Optimal Fiscal Policy, Baltimore: The Johns Hopkins University Press.

[12] Becchetti, L., S. Castriota, L. Corrado, E.G. Ricca (2013), Beyond the Joneses: Inter-country income comparisons and happiness, Journal of Socio-Economics, 45, 187-195.

[13] Blanchflower D.G. (2008). International evidence on well-being. IZA Discussion Paper No. 3354.

[14] Brekke, K. A., R. B. Howarth (2002), Status, Growth and the Environment. Goods as Symbols in Applied Welfare Economics, Cheltenham: Edward Elgar.

[15] Carroll, C.D., J.R. Overland, D.N. Weil (1997), Comparison Utility in a Growth Model, Journal of Economic Growth 2, 339-367.

[16] Clark, A.E., P. Frijters, M.A. Shields (2008), Relative Income, Happiness, and Utility: An Explanation for the Easterlin Paradox and other Puzzles, Journal of Economic Literature 46, 95-114.

[17] Clark, A.E., C. Senik (2010), Who Compares to Whom? The Anatomy of Income Com- parisons in Europe, Economic Journal 120, 573-594.

[18] Clark, A.E. and C. Senik (2011), Will GDP Growth Increase Happiness in Developing Countries? IZA Discussion Paper No. 5595.

[19] Corneo, G., O. Jeanne (1997), On Relative-wealth Effects and the Optimality of Growth, Economics Letters 54, 87-92. 
[20] Corneo, G., O. Jeanne (2001), On Relative Wealth Effects and Long-run Growth, Research in Economics 55, 349-358.

[21] Croushore, D. (1993), Money in the Utility Function: Functional Equivalence to a Shopping-Time Model, Journal of Macroeconomics 15, 175-182.

[22] Darwin, C. (1871), The Descent of Men and Selection in Relation to Sex, London: John Murray.

[23] Deloitte report (2017), Global powers of luxury goods 2017. The new luxury consumer, Deloitte University, EMEA CVBA.

[24] Dodds, S. (2012), Redistributive Taxation and Heterogeneous Relative Consumption Concerns, Canadian Journal of Economics 45, 220-246.

[25] Easterlin, R. (1995), Will Raising the Incomes of All Increase the Happiness of All? Journal of Economic Behavior \& Organization 47, 35-47.

[26] Euromonitor International (2016), SUVs Become the Largest and Fastest-Growing Automotive Segment in 2015, Web, https://blog.euromonitor.com/2016/09/suvs-become-largest-fastest-growingautomotive-segment-2015.html.

[27] Fisher, W.H., B.J. Heijdra (2009), Keeping up with the Ageing Joneses, Journal of Economic Dynamics and Control 33, 53-64.

[28] Fisher, W.H., F.X. Hof (2000), Relative Consumption, Economic Growth, and Taxation, Journal of Economics 72, 241-262.

[29] Fisher, W.H., F.X. Hof (2005), Status Seeking in the Small Open Economy, Journal of Macroeconomics 27, 209-232.

[30] Frank, R.H. (2005), Positional Externalities Cause Large and Preventative Welfare Distortions, American Economic Review 95, 137-141. 
[31] Frank, R.H. (2008), Should Public Policy Respond to Positional Externalities? Journal of Public Economics 92, 1777-1786.

[32] Futagami, K., A. Shibata (1998), Keeping One Step Ahead of the Joneses: Status, the Distribution of Wealth, and Long Run Growth, Journal of Economic Behavior \& Organization 36, 93-111.

[33] Ghosh, S., R. Wendner (2018), Positional Preferences, Endogenous Growth, and Optimal Income- and Consumption Taxation, Oxford Economic Papers 70, 114-140.

[34] Goodin, R.E. (1986), Laundering Preferences, in: Elster, J., A. Hylland, Foundations of Social Choice Theory, Cambridge: Cambridge University Press.

[35] Harsanyi, John C. (1977), Rule Utilitarianism and Decision Theory, Erkenntnis 11(1), 25-53.

[36] Harsanyi, J. (1982), Morality and the Theory of Rational Behavior, in: Sen, A., B. Williams (eds.), Utilitarianism and Beyond, Cambridge: Cambridge University Press.

[37] Hof, F.X., F. Wirl (2008), Wealth Induced Multiple Equilibria in Small Open Economy Versions of the Ramsey Model, Homo Oeconomicus 25, 107-128.

[38] James, J. (1987), Positional goods, conspicuous consumption and the international demonstration effect reconsidered, World Development, 15 (4), 449-462.

[39] Johansson-Stenman, O., F. Carlsson, D. Daruvala (2002), Measuring Future Grandparents' Preferences for Equality and Relative Standing, Economic Journal 112, 362-383.

[40] Johansson-Stenman, O., P. Martinsson (2006), Honestly, Why Are You Driving a BMW?, Journal of Economic Behavior \& Organization 60, 129-146. 
[41] Kanbur, R., J. Pirtill, M. Tuomala (2006), Non-welfarist optimal taxation and behavioral public economics, Journal of Economic Surveys 20, 849-868.

[42] Kanbur, R, M. Tuomala (2010), Relativity, Inequality and Optimal Nonlinear Income Taxation, Tampere University, Working paper no. 75.

[43] Kanbur, R., M. Tuomala (2013), Relativity, Inequality and Optimal Nonlinear Income Taxation, International Economic Review 54, 1199-1217.

[44] Kaplow, L. (2009), Utility from Accumulation, Proceedings. Annual Conference on Taxation and Minutes of the Annual Meeting of the National Tax Association 102, 189-194.

[45] Kumhof, M., R. Rancière, P. Winant (2015), Inequality, Leverage, and Crises, American Economic Review 105, 1217-1245.

[46] Kurz, M. (1968), Optimal Economic Growth and Wealth Effects, International Economic Review 9, 348-357.

[47] Liu, W.F., S.J. Turnovsky (2005), Consumption Externalities, Production Externalities, and Long-Run Macroeconomic Efficiency, Journal of Public Economics 89, 1097-1129.

[48] Markowitz, H. (1952), The Utility of Wealth, Journal of Political Economy 60, 151-158.

[49] Micheletto, L. (2011), Optimal Nonlinear Redistributive Taxation and Public Good Provision in an Economy with Veblen Effects, Journal of Public Economic Theory 13, 71-96.

[50] Nakamoto, Y. (2009), Jealousy and over-saving in a One-sector Model with Wealth Preference, Journal of Economic Dynamics and Control 33, 2015-2029.

[51] OECD (2017), Social Expenditure - Aggregated Data (SOCX), Web, https://stats.oecd.org/Index.aspx?DataSetCode=SOCX_AGG. 
[52] Pham, T.K.C. (2005), Economic Growth and Status-seeking through Personal Wealth, European Journal of Political Economy 21, 404-427.

[53] Pigou, A. C. (1941), Employment and Equilibrium: A Theoretical Discussion, London: Macmillan.

[54] Piketty, T., E. Saez (2013), Optimal Labor Income Taxation, in: Auerbach, A., R. Chetty, M. Feldstein, E. Saez, Handbook of Public Economics, Vol. 5, Elsevier-North Holland.

[55] Rauscher, M. (1997), Conspicuous Consumption, Economic Growth, and Taxation, Journal of Economics 66, 35-42.

[56] Rebelo, S. (1991), Long Run Policy Analysis and Long Run Growth, Journal of Political Economy 99, 500-521.

[57] Rehme, G. (2017), "Love of Wealth" and Economic Growth, Review of Development Economics 21, 1305-1326.

[58] Sen, A.K. (1979), Personal Utilities and Public Judgements: or What's Wrong with Welfare Economics, Economic Journal 89, 537-558.

[59] Smith, A. (1759), The Theory of Moral Sentiments, in: The Theory of Moral Sentiments, republished in 1976, Oxford: Oxford University Press.

[60] Solnick, S.J., D. Hemenway (1998), Is More Always Better? A Survey on Positional Concerns, Journal of Economic Behavior \& Organization 37, 373383.

[61] Solnick, S.J., D. Hemenway (2005), Are Positional Concerns Stronger in Some Domains than in Others?, American Economic Review 95, 147-151.

[62] Stewart, F. (1977), Technology and Underdevelopment, London: Macmillan. 
[63] Turnovsky, S.J., G. Monteiro (2007), Consumption Externalities, Production Externalities, and Efficient Capital Accumulation Under Time Non-Separable Preferences, European Economic Review 51, 479-504.

[64] Truyts, T. (2010), Social Status in Economic Theory, Journal of Economic Surveys 24, 137-169.

[65] Tournemaine, F., C. Tsoukis (2008), Relative Consumption, Relative Wealth and Growth, Economics Letters 100, 314-316.

[66] Veblen, T. (1899) The Theory of the Leisure Class, in: The Theory of the Leisure Class, republished in 1973, Boston: Houghton-Mifflin.

[67] Weber, M. (1930), The Protestant Ethic and the Spirit of Capitalism, London: Allen \& Unwin.

[68] Wendner, R. (2014), Ramsey, Pigou, Heterogeneous Agents, and Nonatmospheric Consumption Externalities, Journal of Public Economic Theory $16,491-521$.

[69] Zou, H. (1994), 'The Spirit of Capitalism' and Long-Run Growth, European Journal of Political Economy 10, 279-293.

[70] Zou, H. (1995), The Spirit of Capitalism and Savings Behavior, Journal of Economic Behavior \& Organization 28, 131-143. 